\title{
Towards a 'chassis' for bacterial magnetosome biosynthesis: genome streamlining of Magnetospirillum gryphiswaldense by multiple deletions
}

Theresa Zwiener ${ }^{1} \mathbb{B}$, Marina Dziuba ${ }^{1,2}$, Frank Mickoleit ${ }^{1}$, Christian Rückert ${ }^{3}$, Tobias Busche ${ }^{3}$, Jörn Kalinowski ${ }^{3}$, René Uebe ${ }^{1}$ and Dirk Schüler ${ }^{1 *}$

\begin{abstract}
Background: Because of its tractability and straightforward cultivation, the magnetic bacterium Magnetospirillum gryphiswaldense has emerged as a model for the analysis of magnetosome biosynthesis and bioproduction. However, its future use as platform for synthetic biology and biotechnology will require methods for large-scale genome editing and streamlining.

Results: We established an approach for combinatory genome reduction and generated a library of strains in which up to 16 regions including large gene clusters, mobile genetic elements and phage-related genes were sequentially removed, equivalent to $\sim 227.6 \mathrm{~kb}$ and nearly $5.5 \%$ of the genome. Finally, the fragmented genomic magnetosome island was replaced by a compact cassette comprising all key magnetosome biosynthetic gene clusters. The prospective 'chassis' revealed wild type-like cell growth and magnetosome biosynthesis under optimal conditions, as well as slightly improved resilience and increased genetic stability.

Conclusion: We provide first proof-of-principle for the feasibility of multiple genome reduction and large-scale engineering of magnetotactic bacteria. The library of deletions will be valuable for turning M. gryphiswaldense into a microbial cell factory for synthetic biology and production of magnetic nanoparticles.
\end{abstract}

Keywords: Magnetospirillum gryphiswaldense, Magnetotactic bacteria, Magnetosomes, Genome reduction, Chassis, IS elements

\section{Background}

Magnetosomes are membrane-enclosed organelles that are synthesized by various aquatic bacteria for their magnetotactic navigation in the Earth's geomagnetic field $[1,2]$. Apart from their biological function as magnetic sensors, magnetosomes also represent microbially synthesized magnetic nanoparticles (MNP) consisting of monocrystalline magnetite $\left(\mathrm{Fe}_{3} \mathrm{O}_{4}\right)$ or greigite $\left(\mathrm{Fe}_{3} \mathrm{~S}_{4}\right)$.

\footnotetext{
*Correspondence: dirk.schueler@uni-bayreuth.de

${ }^{1}$ Department of Microbiology, University of Bayreuth, Bayreuth, Germany

Full list of author information is available at the end of the article
}

Because of their strictly controlled biomineralization, bacterial magnetosomes have exceptional properties, such as high chemical purity and crystallinity, strong magnetization, and uniform sizes and shapes, which are largely unknown from chemically synthesized MNP [3-5]. This makes them highly attractive for a number of biotechnological and biomedical applications [6-8]. For examples, magnetosomes isolated from the magnetic bacterium Magnetospirillum gryphiswaldense were successfully tested as multimodal reporters for magnetic imaging $[9,10]$, nanocarriers for magnetic drug targeting [11-13], and for magnetic hyperthermia applications [14,

c) The Author(s) 2021. This article is licensed under a Creative Commons Attribution 4.0 International License, which permits use, sharing, adaptation, distribution and reproduction in any medium or format, as long as you give appropriate credit to the original author(s) and the source, provide a link to the Creative Commons licence, and indicate if changes were made. The images or other third party material in this article are included in the article's Creative Commons licence, unless indicated otherwise in a credit line to the material. If material is not included in the article's Creative Commons licence and your intended use is not permitted by statutory regulation or exceeds the permitted use, you will need to obtain permission directly from the copyright holder. To view a copy of this licence, visit http://creativeco mmons.org/licenses/by/4.0/. The Creative Commons Public Domain Dedication waiver (http://creativecommons.org/publicdomain/ zero/1.0/) applies to the data made available in this article, unless otherwise stated in a credit line to the data. 
15]. In addition, the functionality of magnetosomes can be extended by genetically fusing foreign functional moieties and polypeptides, such as fluorophores, enzymes, antibodies, and organic shells [16-22] to magnetosome membrane anchors. Moreover, the bacteria were utilized as a model to study the molecular mechanisms of human diseases related to homologs of certain magnetosome proteins [23].

However, applications of bacteria and their magnetosomes so far have been hampered by the limited number of appropriate production strains and difficulties in their large-scale cultivation and genetic manipulation. One of the most extensively investigated model organisms for studying magnetosome biosynthesis is the freshwater alphaproteobacterium M. gryphiswaldense [24, 25]. It typically produces 15-25 cuboctahedral magnetite particles per cell that are about $40 \mathrm{~nm}$ in size [26], while genetic overexpression of gene clusters governing magnetosome biosynthesis generated an overproducing strain forming $>100$ (up to 170) particles per cell with enlarged sizes [27]. Because of its genetic tractability and relatively straightforward cultivation, M. gryphiswaldense recently has also emerged as host strain for bioproduction and synthetic biology of magnetosomes [20, 21, 27-31].

Despite of this recent progress, since its isolation $[24,32,33]$ the usability of the undomesticated M. gryphiswaldense as a biotechnological workhorse has been limited due to several unwanted features. For example, one obstacle is the rather fastidious and sometimes fluctuating growth, which makes cultivation difficult to reproduce at larger scale. In other bacteria, this erratic growth behavior has been attributed to the presence of prophage genes, which are often known to exhibit some latent activity, resulting in a negative impact on the robustness of growth and the performance of bioprocesses [34-36]. Another adverse feature is the inherent genetic instability of $M$. gryphiswaldense, and in particular of the magnetic phenotype, which makes genetic manipulation and magnetosome production cumbersome. For example, spontaneous loss or impairment of magnetosome biosynthesis has been observed frequently during subcultivation, which had been traced back to spontaneous deletions and rearrangements within the large genomic magnetosome island (MAI) [37-39]. This chromosomal region extends across about $100 \mathrm{~kb}$ and comprises discontiguous clusters of more than 30 genes responsible for magnetosome formation organized in the five polycistronic operons feoAB1, mms6, mamGFDC, mamAB and $\operatorname{mam} X Y[1,40]$. In addition, the MAI harbors regions of irrelevant gene content and numerous mobile genetic elements, which might be responsible for the frequent rearrangements and loss of magnetic phenotype in M. gryphiswaldense [37, 38, 41].
For future synthetic biology applications as well as large-scale magnetosome bioproduction, a simplified and potentially more robust version of the M. gryphiswaldense genome would be highly beneficial. In other bacteria, moderate genome reduction, which comprises the targeted deletion of multiple dispensable genes, has been shown to optimize metabolic pathways, enhance the expression of recombinant protein productivity, and improve physiological performance and growth [42-46]. For instance, by removing non-essential, recombinogenic or mobile DNA and cryptic virulence genes, genome reduction of Escherichia coli resulted in several favorable properties, such as increased electroporation efficiency and improved propagation of recombinant genes [47]. Deletion of prophage genes improved growth and transformation efficiency in Corynebacterium glutamicum [34], enhanced genotypic stability in Pseudomonas putida [35, 48, 49], and increased robustness toward stress in Vibrio natriegens or Shewanella oneidensis MR-1 [36, 50]. Furthermore, deletion of active mobile genetic elements caused enhanced protein productivity in C. glutamicum [51], and increased transformability and reduced mutation rates in Acinetobacter baylyi [52].

In magnetotactic bacteria, comparable genome reduction approaches so far have been impeded because of the unavailability of efficient methods for large-scale engineering of these recalcitrant microorganisms. To overcome these current limitations, we recently started a systematic approach to engineer the model strain M. gryphiswaldense at the genome level. In a previous study, we established a method for large-scale deletion mutagenesis and utilized it for the generation of 24 single deletions covering about $167 \mathrm{~kb}$ of non-redundant genome content. We thereby identified large regions inside and outside the MAI irrelevant for magnetosome biosynthesis [53]. Here, we continued our work by constructing genome-reduced strains of $M$. gryphiswaldense with multiple combinatorial deletions of irrelevant and detrimental gene content. We provide a proof of concept for large-scale genome editing and improvement towards a future chassis [54], which may turn M. gryphiswaldense into a microbial cell factory for the synthetic biology and high-yield production of magnetic nanoparticles.

\section{Results}

\section{Overview over the experimental strategy}

The features of a genome reduced future 'chassis' should include first the elimination of problematic and harmful gene content such as prophage genes as well as active IS elements known to cause genetic instability [50-52]. Second, the genome should be freed of as much of gene content unnecessary for magnetosome biosynthesis, growth 
and fitness under lab conditions as possible. Third, neutral and favorable scarless deletions should be combined into one or few single strains. Ultimately, the native biosynthetic gene clusters within the MAI plus multiple large portions of 'junk' between and adjacent to them should be substituted by a compact cassette comprising all key genes for magnetosome biosynthesis (plasmid pMDJM3). Final strains were tested for growth, fitness, and genetic stability (for an overview over the experimental workflow see Fig. 1a).

\section{Identification and elimination of prophage genes}

Since its isolation $[24,32,33]$, our lab persistently experienced occasional problems with the cultivation of $M$. gryphiswaldense, such as poorly reproducible and fluctuating growth, which could not only be explained by unintended subtle variations in handling, media constituents and incubation alone. In other bacteria, similar observations could be traced back to the latent activity and induction of prophages, which are known to often have a negative impact on robustness of growth and the performance of bioprocesses [34]. In the genome of $M$. gryphiswaldense, we detected seven putative prophage regions (referred to as P1-P7) (Fig. 1b) by the phage search tool PHAST [55]. Two of them (P1, $26 \mathrm{~kb}$, and P6, $34.1 \mathrm{~kb}$ ) were predicted as intact (Figs. $1 \mathrm{~b}$ and $2 \mathrm{a}, \mathrm{b}$ ), but upon closer inspection only P6 is contiguous and seems to have a full complement of typical phage genes (e.g. integrases, tail, and major capsid proteins), whereas P1 is interspersed with tRNA genes (Fig. 2a, b). Predicted prophage P2 seems to be incomplete as well, consistent with its small size $(7.2 \mathrm{~kb})$ and its accumulation of several transposon genes. Region P3 (20 kb) comprises some putative essential genes (e.g. encoding transcriptional regulators, chaperones) and a phage integrase intA1. Incomplete P4 $(31.2 \mathrm{~kb})$ and P5 (14.3 kb) are also interspersed with genes of unrelated, but important functions, e.g. chaperones of DnaJ-class, a transcriptional regulator and a ribonuclease, respectively. Incomplete P7 (11.3 kb) resides inside the part of the MAI (Fig. 1b) that was nondeletable in previous experiments [53]. From the identified putative phages, the following regions were selected as targets for deletion: P1 was divided into two parts excluding the essential tRNA genes (P1.2, $19.4 \mathrm{~kb}$, and P1.3, $12.8 \mathrm{~kb}$ ) that were both deleted separately (Fig. 2a). Since deletion of whole P6 failed, only genes encoding putative capsid proteins $(7.65 \mathrm{~kb})$ and a recombinase (hin2, 1.34 kb) were deleted separately (Fig. 2b). Furthermore, inside and adjacent to these predicted prophages, we identified several putative integrases and excisionases that might be involved in the reactivation of lysogenic prophages to the lytic cycle and decided to delete several candidates as well (intA1 $1.28 \mathrm{~kb}$, intA2 $1.22 \mathrm{~kb}$ and alpA 225 bp) (Fig. 1b).

Under aerobic and anaerobic conditions, growth of all prophage deletants was largely indistinguishable from the WT (data not shown). After incubation with $0.2 \mu \mathrm{g} / \mathrm{ml} \mathrm{MMC}$, which is known to trigger the cellular SOS response and to induce prophages to enter the lytic cycle $[36,56]$, growth was indistinguishable from the WT for most deletants. A notable exception was $\Delta$ hin2 (msr1_37790), which proved to be less sensitive and could be re-grown after incubation with up to $0.3 \mu \mathrm{g} / \mathrm{ml}$ MMC (Fig. 2c).

\section{Deletion of active mobile genetic elements}

Previous observations had revealed a genetic instability of the $M$. gryphiswaldense WT strain: first, the ability to form magnetosomes often became spontaneously reduced or lost entirely, which had been hypothesized to be caused by the presence and activity of numerous mobile elements, resulting in insertions by transposition activity [53], plus deletions and rearrangements caused by homologous recombination between identical copies [37, 38, 41]. Second, during the course of routine genetic manipulation, we frequently also observed spontaneous inactivation of introduced foreign genes, such as chromogenic reporters (e.g. gusA, unpublished observations) or genetic markers for antibiotic or counterselection (e.g. galK) [53]. Our preliminary analysis revealed that inactivation was often due to insertion of mobile genetic elements belonging to two types, each with two variants: the first type is a bipartite insertion element (in the following referred to as ISMgr2; Fig. 3a), composed of genes encoding a putative IS2 repressor TnpA, and an IS2 transposase TnpB, respectively. ISMgr 2 belongs to the IS3 family that is common in many $\alpha$-Proteobacteria [57]. Three copies of ISMgr2 (ISMgr2-1, ISMgr2-2 and ISMgr2-3) with $99.8 \%$ protein identity $(99.9 \%$ nucleotide identity) are present in the genome of M. gryphiswaldense (Fig. 3a), with one of them residing within the MAI (Fig. 1b, ISMgr2-3). Two additional homologs of tnpB, termed ISMgr2-tnpB-hyp-1 and ISMgr2-tnpB-hyp-2, with lower $(20.8 \%)$ protein identity ( $52.6 \%$ nucleotide identity) compared to the first three copies ISMgr2-1, ISMgr2-2 and ISMgr2-3 (Fig. 3b) could be identified. Each of these latter two homologs are associated with two conserved hypothetical genes upstream of the IS2 transposon gene $\operatorname{tnp} B$ instead of $\operatorname{tnp} A$. We first deleted each of the five homologs individually in the WT background (1-1.25 kb each). As expected, single deletion mutants of all five strains displayed WT-like growth and magnetosome biosynthesis under aerobic and anaerobic conditions, and under oxidative and moderate heat stress (data not 
a

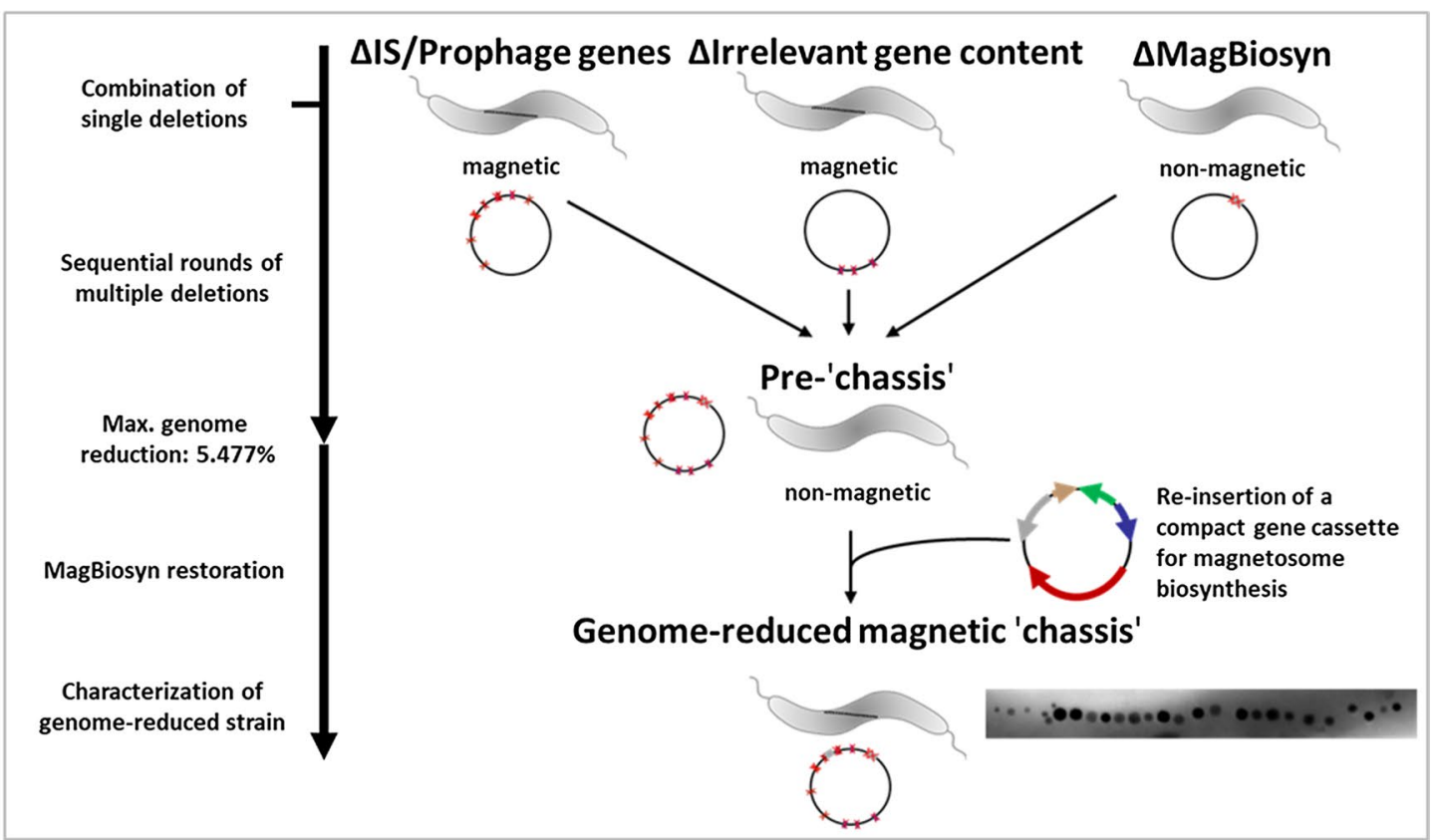

b

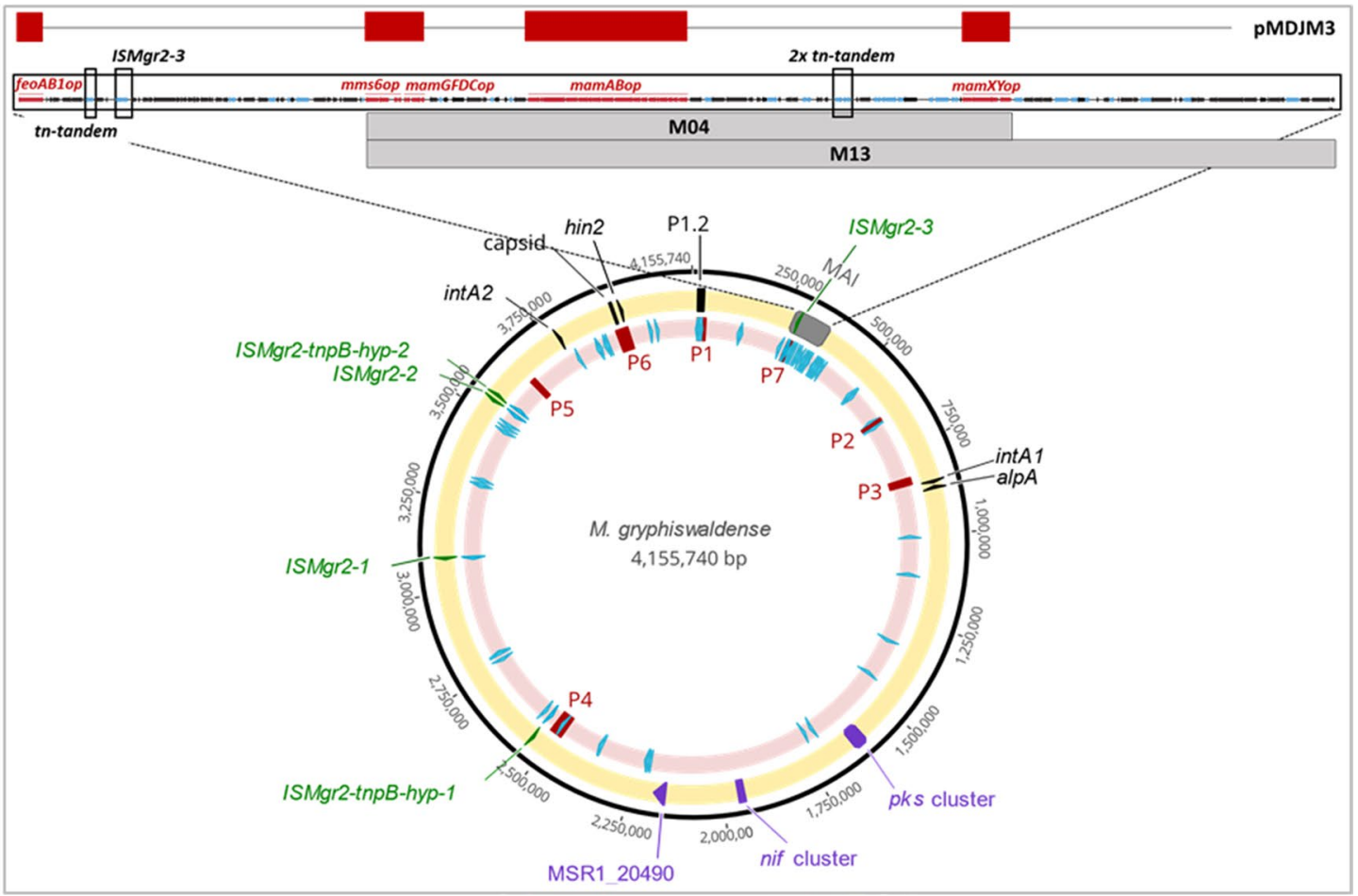

Fig. 1 Overview over the experimental workflow (a), and the genomic positions of deletion targets in M. gryphiswaldense (b). Yellow circle (b) shows genes or gene sets targeted for multiple deletions. Grey: magnetosome island (MAl); black arrows: parts of predicted prophage sets and phage-related integrase and excisionase genes; green arrows: insertion element genes identified as most active in this study; purple: irrelevant gene clusters. Pink circle (b) indicates predicted prophage sets (dark red) and mobile genetic elements (light blue). The enlarged area shows the genetic organization of the native MAI with all five known magnetosome biosynthesis operons (red), genes of known or unknown function irrelevant for magnetosome formation (black), mobile genetic elements (light blue). The grey bars indicate the extent of regions M04 ( 65 kb) and M13 ( $100 \mathrm{~kb}$ ), which were shown to be deletable en bloc in our previous study [53]. The presence of key magnetosome biosynthesis genes within the compact expression cassette of the applied vector pMDJM3 is indicated by red bars while connecting lines designate eliminated gene content 

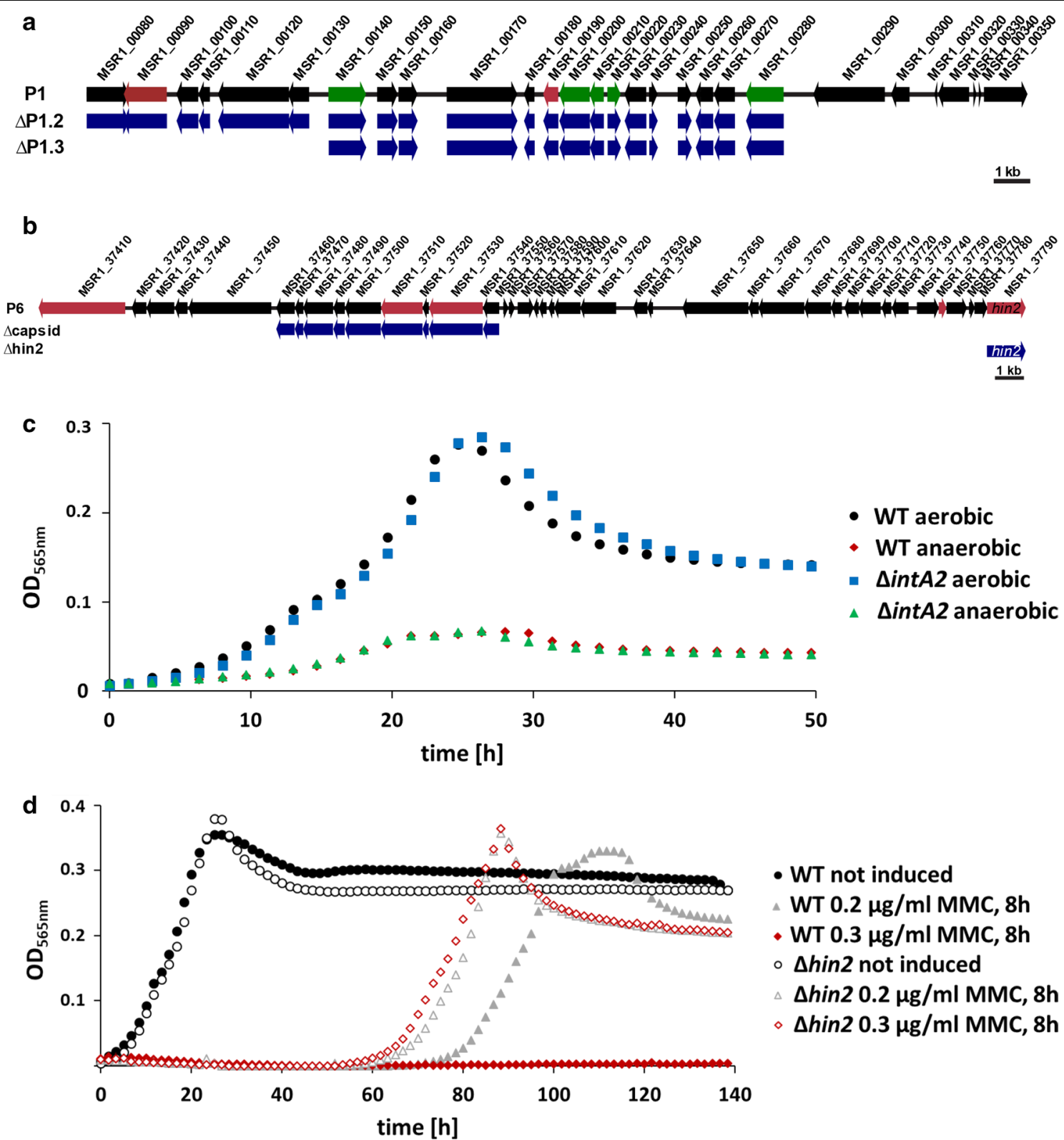

Fig. 2 Molecular organization and analysis of predicted prophages P1 (a), P6 (b), deleted genes and growth characteristics of selected cultures (c, d). a, b Black: hypothetical genes or genes with known function; red: putative prophage genes; green: mobile genetic elements; blue: deleted genes. c Growth characteristics of $\triangle$ intA2 under aerobic and anaerobic conditions compared to WT. Growth of other prophage deletants (not shown) was virtually identical. $\mathbf{d}$ Growth profiles of mitomycin C-treated (MMC) cultures of a selected single prophage deletion mutant and the WT. Cultures were incubated for $8 \mathrm{~h}$ at MMC concentrations of 0.2 or $0.3 \mu \mathrm{g} / \mathrm{ml}$, washed twice, and adjusted to the initial OD. Growth experiments were performed at $28^{\circ} \mathrm{C}$ under aerobic conditions. Each strain was analyzed in triplicates, the curve represents the calculated average (standard deviations were $<5 \%)$

shown). We therefore later decided to sequentially delete these five homologs altogether (see below strains $\Delta \mathrm{TZ}$ 05, $\Delta$ TZ-06, $\Delta$ TZ-09, $\Delta$ TZ-10 and $\Delta$ TZ-11 in Fig. 4).

The second type of active mobile elements is represented by a transposon tandem (tn-tandem) of genes sharing $52.3 \%$ nucleotide identity $(31.25 \%$ protein identity) (Fig. 3c): its first gene $(\operatorname{tn} 1)$ encodes a putative transposase of the IS4/5 family [57], and the second gene $(t n 2)$ a DDE domain transposase [57] (Fig. 3c). This tandem pair is present in the genome of M. gryphiswaldense in 19 identical (100\% nt) copies, and in addition $t n 2$ alone in two more identical single copies. Four of the 19 


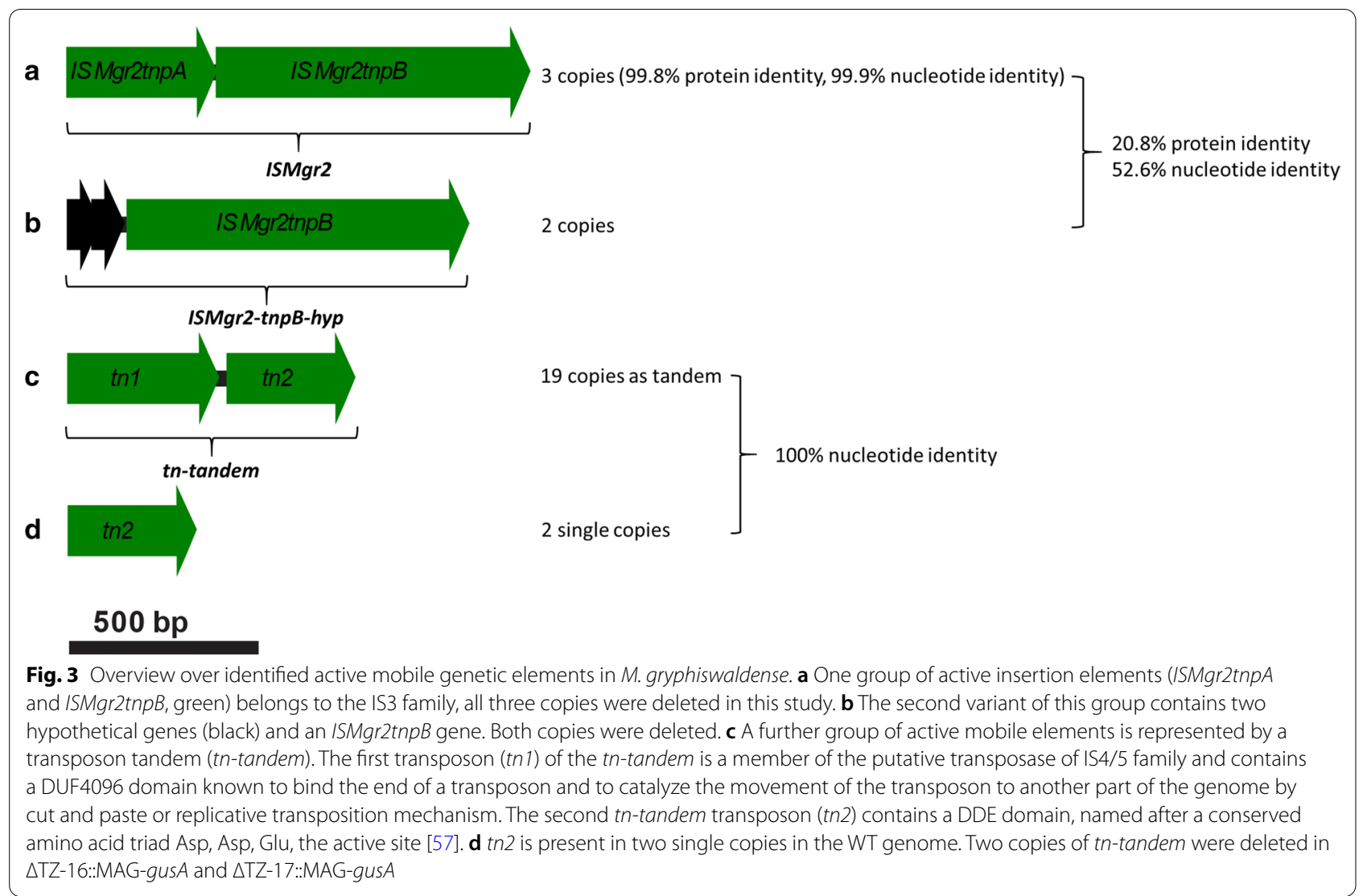

tn-tandem pairs reside within the MAI, with two of them comprised within the deletable regions M04 and M13 [53] (Fig. 1b). However, due to the unavailability of multiplex genetic tools for M. gryphiswaldense, the high copy number of the tn-tandem pairs proved prohibitive for sequential or simultaneous deletion of all copies.

\section{Identification and elimination of further gene clusters} irrelevant for cell growth and magnetosome biosynthesis

Next, to eliminate further larger non-essential chromosomal stretches outside the MAI, we exemplary targeted two gene clusters that are likely irrelevant for magnetosome biosynthesis and fitness in lab conditions (Additional file 1: Table S1): (i) A nif operon comprising 16 genes, namely nifWABZTHDK, fixABC, draGT and three ferredoxin genes (msr1_18560; msr1_18600; msr1_18640). The nif operon is likely linked to nitrogen fixation in M. gryphiswaldense [58] (Additional file 1: Fig. S1) which is irrelevant under the denitrifying conditions optimal for magnetosome biosynthesis [28]. We generated a mutant in which $\sim 20 \mathrm{~kb}$ of this nif cluster comprising 20 genes were deleted (Additional file 1: Fig. S1). (ii) Several uncharacterized clusters encoding a putative non-ribosomal peptide synthetase (NRPS) and a polyketide synthase (PKS) were predicted [59]. Since it was unlikely to be necessary for magnetosome biosynthesis, we deleted three large ORFs encoding putative PKS proteins from one of the clusters (termed $p k s$ ) extending over $40 \mathrm{~kb}$ (Fig. 1b; Additional file 1: Table S1). As expected, strains harboring single deletions in nif or $p k s$ clusters were indistinguishable from the WT with regard to magnetosome formation, cell growth and motility, which confirmed their irrelevance for magnetosome biosynthesis and fitness under lab conditions (Additional file 1: Table S1, Fig. S4).

\section{Combinatory mutagenesis}

In order to combine all previously tested favorable or neutral deletions into one or two single strains, we employed the following strategy (Fig. 4): starting with the $\triangle i n t A 2$ strain as a parent, we first proceeded by deleting further selected prophage genes $(\Delta \mathrm{TZ}-01-\Delta \mathrm{TZ}-04)$, then continued with the mobile genetic elements $(\Delta \mathrm{TZ}-05$ and $\triangle \mathrm{TZ}-06)$ and further prophage genes and IS elements $(\Delta \mathrm{TZ}-07-\Delta \mathrm{TZ}-11)$ and ended with deletion of irrelevant gene clusters and magnetosome biosynthesis genes $(\Delta \mathrm{TZ}-12-\Delta \mathrm{TZ}-17)$. One round of deletion was completed as soon as the loss of kanamycin resistance marker 


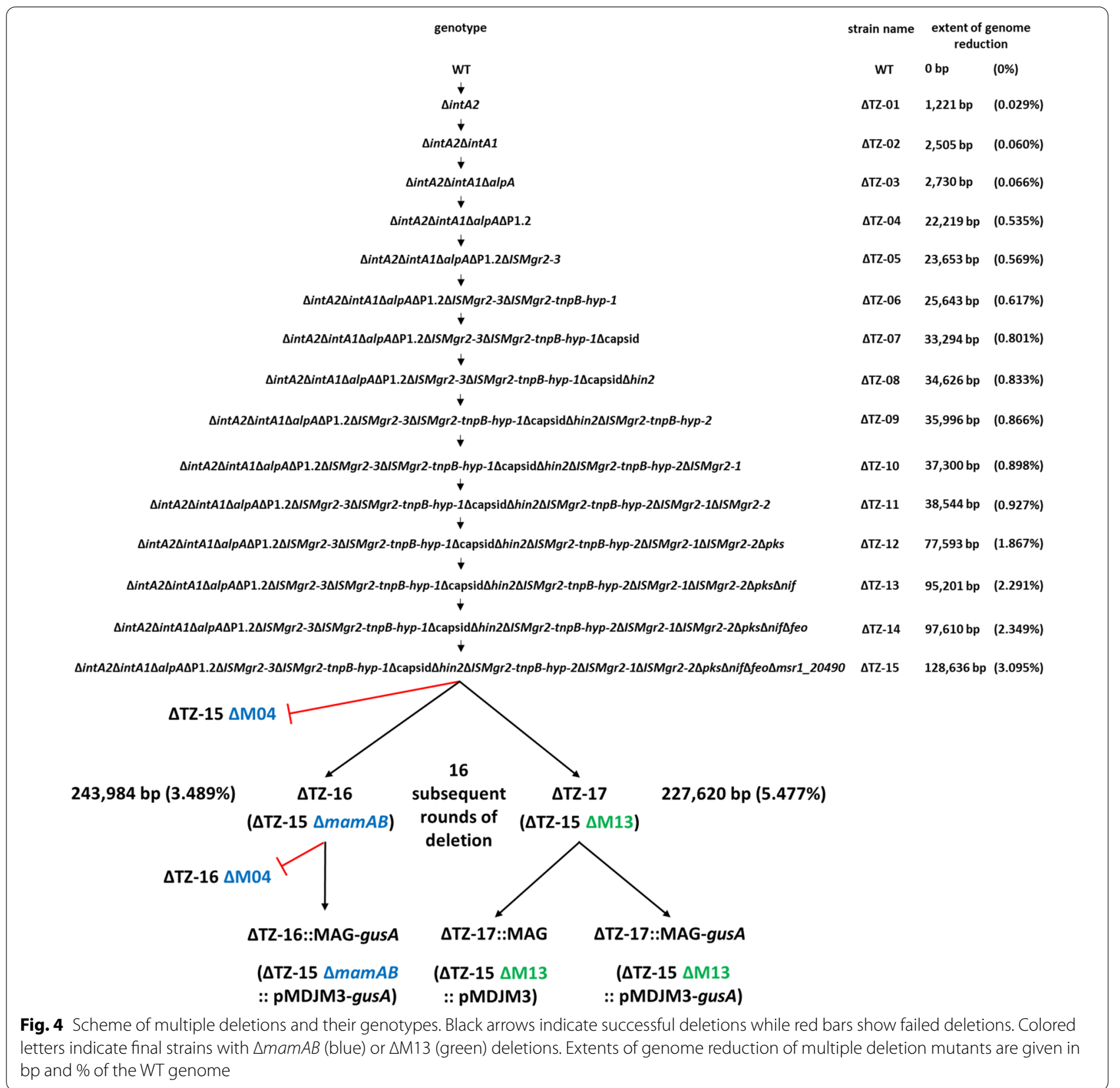

$\left(\mathrm{Km}^{\mathrm{r}}\right)$ was verified by replica plating. After each round, magnetic responses of mutant strains as well as their growth under aerobic and anaerobic conditions, oxidative and moderate heat stress were tested. This was found to be WT-like for all offspring strains including $\Delta \mathrm{TZ}-15$ (Additional file 1: Fig. S2).

After fifteen successful rounds of deletions, the resulting mutant $\triangle \mathrm{TZ}-15$ was used as a parent to delete large parts of the MAI including all magnetosome biosynthesis operons. In a previous study, a contiguous stretch of $\sim 66 \mathrm{~kb}$ termed region M04 was found to be deletable in the WT-background, including all mam and mms6 operons $(\sim 27 \mathrm{~kb})$ plus $\sim 39 \mathrm{~kb}$ of irrelevant or problematic gene content, such as two copies of tn-tandem (Fig. 1b, enlargement, grey bar) [53]. This had no obvious effects on growth, and magnetosome biosynthesis could be restored to WT-level by complementation with a compact expression cassette comprising the mam and mms 6 operons only [53]. In addition, a $\sim 100 \mathrm{~kb}$ region termed M13 (Fig. 1b) could be excised, again including all mam and mms6 operons, plus an additional $\sim 33 \mathrm{~kb}$ flanking region. Despite of its slightly impaired growth in 
oxidative stress conditions [53], the M13 region was chosen as an additional target to generate a strain with the largest possible genome reduction.

However, we failed to delete M04 in strain $\Delta \mathrm{TZ}-15$ despite of several attempts (Fig. 4), although its deletion had been readily achieved before in the WT background [53]. Instead, upon repeated attempts of conjugation and counterselection, we obtained a number of conspicuous clones with either magnetic or non-magnetic phenotypes, which had supposedly excised the deletion target as suggested by PCR, but lost their insensitivity against kanamycin, indicating that parts of the suicide vector harboring the $\mathrm{Km}^{\mathrm{r}}$ marker were likely still maintained in the genome. In our previous study, similar observations could be traced back to the inactivation of the galK gene encoding the lethal galactokinase, followed by spontaneous rearrangements in the absence of rigorous counterselection [53]. This explained our failure to enforce the proper deletion during counterselection in the presence of galactose, and in fact, the entire M04 region was still present in the genome (see Additional file 1: Fig. S3 for detail). To circumvent this problem, we separately deleted the essential mamABop first in strain $\triangle T Z-15$, yielding strain $\triangle \mathrm{TZ}-16$, in which we attempted subsequent deletion of the residual M04 region. Several kanamycin sensitive $\left(\mathrm{Km}^{\mathrm{s}}\right)$, non-magnetic clones were obtained in this regime, which however again yielded diverse PCR products only roughly similar to the expected size spanning over the targeted excision site. Nevertheless, one of the clones (still tentatively termed $\Delta \mathrm{TZ}-16$ ), was selected as parent for later re-insertion of pMDJM3 harboring a compact version of the magnetosome biosynthesis gene clusters (see below).

In contrast to the troublesome M04 deletion, one-step deletion of the even larger region M13 in the background of $\Delta \mathrm{TZ}-15$ was obtained readily and yielded plenty of expected non-magnetic clones, in which the proper deletion of M13 could be confirmed by PCR spanning over the targeted excision site. This yielded strain $\Delta \mathrm{TZ}-17$. Like the respective single deletion mutants $\triangle \mathrm{M} 04$ and $\triangle \mathrm{M} 13$ in the WT background [53], both intermediate strains $\Delta \mathrm{TZ}-16$ and $\Delta \mathrm{TZ}-17$ showed conspicuous irregularly shaped electron dense particles (EDPs) between 10 and $125 \mathrm{~nm}$ in size in electron micrographs (see Fig. 6a below, white arrows), which were previously shown to be rich in potassium, phosphorus and oxygen, and to be unrelated to magnetosome biosynthesis [53].

In the final step, restoration of magnetosome biosynthesis was attempted in the two multiple deletion strains. This was achieved by insertion of PMDJM3 or pMDJM3gusA, variants of pTpsMAG1 [60] harboring the compact set of $\mathrm{mam} / \mathrm{mms} / \mathrm{feo}$ genes and lox sites for restoration of antibiotic resistance to generate a marker-less mutant, and in case of pMDJM3-gusA in addition encoding the enzyme GusA (glucuronidase) as a chromogenic reporter. The gusA gene was added next to the mamXYop as entrapment for spontaneous mutations in a genetic stability assay to $\Delta \mathrm{TZ}-16$ and $\Delta \mathrm{TZ}-17$ (see below). As control, gusA was also inserted into the WT strain at the same genomic position next to the mamXYop as in pMDJM3. The region downstream of mamXYop was chosen as site for gusA insertion, since spontaneous deletions, insertions and rearrangements of this particular region were observed repeatedly as a virtual hotspot during routine genetic manipulation (unpublished observations). This is possibly caused by its close proximity $(\sim 11.4 \mathrm{~kb})$ to the two $t n$-tandem copies described above, and often accompanied by impaired magnetosome phenotypes akin a mamXYop deletion [61]. Thus, the strains $\Delta$ TZ-16::MAG-gusA, $\Delta$ TZ-17::MAG, $\Delta$ TZ-17::MAGgusA and WT-gusA (Fig. 4) were generated.

\section{Genome analysis of final multiple mutant strains}

To verify the multiple introduced deletions, as well as possible unintended mutations and rearrangements that might have occurred during the numerous rounds of manipulation, at this point the two final multiple mutant strains $\Delta \mathrm{TZ}-16:: \mathrm{MAG}-$ gusA and $\triangle \mathrm{TZ}-17::$ MAG were subjected to genome resequencing. In strain $\Delta \mathrm{TZ}-16::$ MAG-gusA this revealed that the region M04, which we attempted to delete in the last step, was still present as already suspected, except for mamABop, which had been removed already in the previous step in $\Delta \mathrm{TZ}-16$. As a consequence, $\triangle \mathrm{TZ}-16:$ :MAG-gus $A$ is merodiploid for all magnetosome operons but mamABop and feoABlop. All introduced mam/mms/feo genes were found to be present next to endogenous mamXYop (Fig. 5a, red box), although some with silent or neutral point mutations. However, conspicuously, the order of the introduced operons (feoAB1-mamAB-mamGFDCmms6-gusA-mamXY) was shuffled compared to their original order on pMDJM3-gusA (mamAB-feoAB1mamXY-gusA-mms6-mamGFDC). Apart from the failed M04 deletion, all other deletions introduced into $\Delta \mathrm{TZ}-16::$ MAG-gusA were exactly as intended. However, besides a number of point mutations, a few larger indel mutations were found in genome regions likely to be irrelevant for magnetosome biosynthesis. These include the PORFM-GalK-M04 suicide vector within $m s r 1 \_03120$ (nt position 305,858), a $178 \mathrm{bp}$ spontaneous deletion at $\mathrm{nt}$ position 2,599,005 in msr1_24320 (encoding a filamentous hemagglutinin) and an insertion of a copy of ISMgr2 at nt position 3,961,873 (with msr1_37870 encoding a phytochrome-like protein).

In $\triangle \mathrm{TZ}-17:: \mathrm{MAG}$ the entire M13 region was confirmed to be deleted exactly as intended (Fig. $5 \mathrm{~b}$, green circle). 

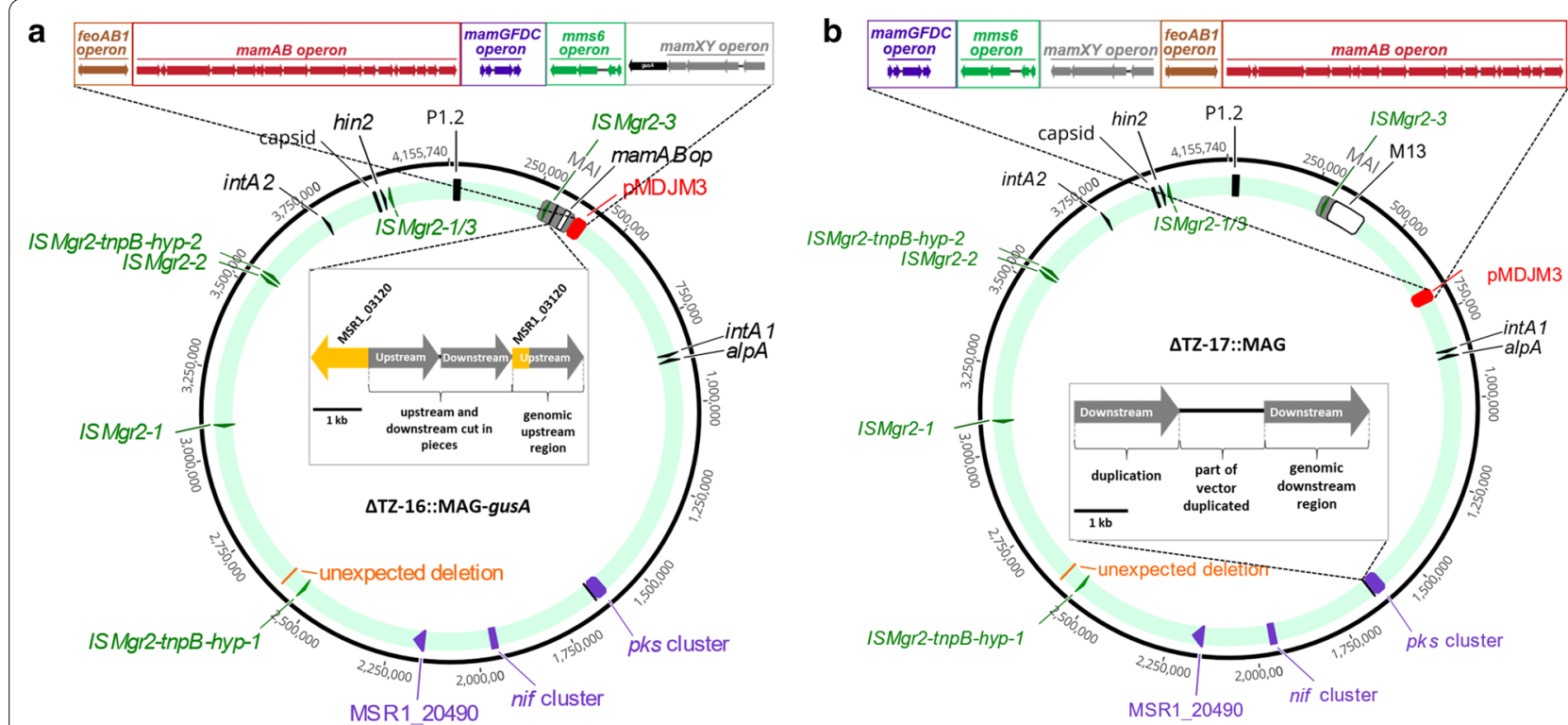

Fig. 5 Schematic presentation showing an overview of $\triangle T Z-16:: M A G-g u S A(\mathbf{a})$ and $\triangle T Z-17:: M A G$ (b) genotypes. Green circle shows the final genotype including unexpected insertions or deletions by resequencing of strains $\triangle T Z-16:$ :MAG-gusA and $\triangle T Z-17:: M A G$. Grey: MAl; white: M13 or mamABop deletions; black arrows: parts of predicted prophage sets, integrase and excisionase genes; green: most active insertion element genes; purple: irrelevant gene cluster. Enlargements indicate unexpected duplication of vector remnants. In $\triangle T Z-16:: M A G-g u s A$ (a) remnants and duplications of up- and downstream regions of PORFM-GalK-M04 suicide vector are still located within msr1_03120 (encoding a putative secreted effector protein PipB) at the position (305,858 nt) targeted for deletion. As observed before, parts of up- and downstream homologous regions were found fragmented and duplicated. PMDJM3-gusA of strain $\triangle T Z-16:: M A G-g u s A$ has been inserted within the intergenic region between mamY (msr1_03880) and the adjacent transposon gene (msr1_03890) (red box). b pMDJM3 in strain $\triangle T Z-17:: M A G$ is located at nt position 699,709 (red box) within the ruvB gene (msr1_07040) encoding a putative holliday junction ATP-dependent DNA helicase. Remnants and duplication of pORFM-GalK-pks suicide vector are located at nt position 1,646,447 (intergenic region upstream of msr1_15660) in strains $\triangle T Z$-16::MAG-gusA and $\triangle T Z-17:: M A G$. Additionally, an unintended spontaneous 178 bp deletion in fhaB 2 gene (msr1_24320) encoding a filamentous hemagglutinin is present at nt position 2,599,005 (green circle, orange), and an insertion of a copy of ISMgr2 at nt position 3,961,873 into cph140 gene (msr1_37870) encoding a phytochrome-like protein was found in both strains (green circle, dark green)

pMDJM3 was inserted at nt position 699,709 (Fig. 5b, green circle, red box). All introduced mam/mms/ feo genes were found to be identical to pMDJM3 with respect to sequences and order. In addition to the successful M13 deletion, also all other introduced deletions were exactly as intended. A short remnant (3 $558 \mathrm{bp}$ ) of suicide vector $p O R F M-G a l K-p k s$ was found inserted at nt position 1,646,447 (considered to be neutral), showing a duplication of the downstream homologous region like in $\triangle \mathrm{TZ}-16:$ :MAG-gusA. Again, the same spontaneous indel mutations in other chromosomal regions as in strain $\Delta$ TZ-16::MAG-gusA were also present in $\triangle \mathrm{TZ}-17:: \mathrm{MAG}$, indicating that these mutations had occurred already at an earlier stage of mutagenesis.

\section{Phenotypic characterization of $\triangle$ TZ-16::MAG-gusA and $\triangle$ TZ-17::MAG-gusA}

Growth characteristics and magnetosome biomineralization Complementation of non-magnetic $\triangle \mathrm{TZ}-16$ (lacking $3.489 \%$ of the WT genome) and $\Delta \mathrm{TZ}-17$ (lacking $5.477 \%$ ) with PMDJM3 restored the formation of WT-like magnetosome numbers and sizes, and cells had electron dense particles (EDP) (Fig. 6a, white arrows), similar as observed before in the corresponding single deletion

(See figure on next page.)

Fig. 6 Phenotypic characterization of multiple deletion mutants. a Electron micrographs of the non-magnetic pre-'chassis'strains $\Delta T Z-16$ and $\triangle T Z-17$ and the final complemented prospective chassis $\triangle T Z-16:: M A G-g u s A$ and $\triangle T Z-17:: M A G-g u s A$ (scale bars 500 nm), white arrows indicate EDPs and $\mathbf{b}$ cell growth under aerobic and anaerobic conditions as well as oxidative stress $\left(\mathrm{H}_{2} \mathrm{O}_{2}\right)$ and heat stress $\left(33^{\circ} \mathrm{C}\right)$. Each strain was analyzed in triplicates and the curves show the average while standard deviation was below 5\%. c Growth curves and $C_{\text {mag }}$ (i.e., a proxy for the average magnetic orientation of bacterial cells in liquid media based on light-scattering [63]) of WT strain and $\triangle T Z-16:$ MAG-gusA during anaerobic fermentation 
a
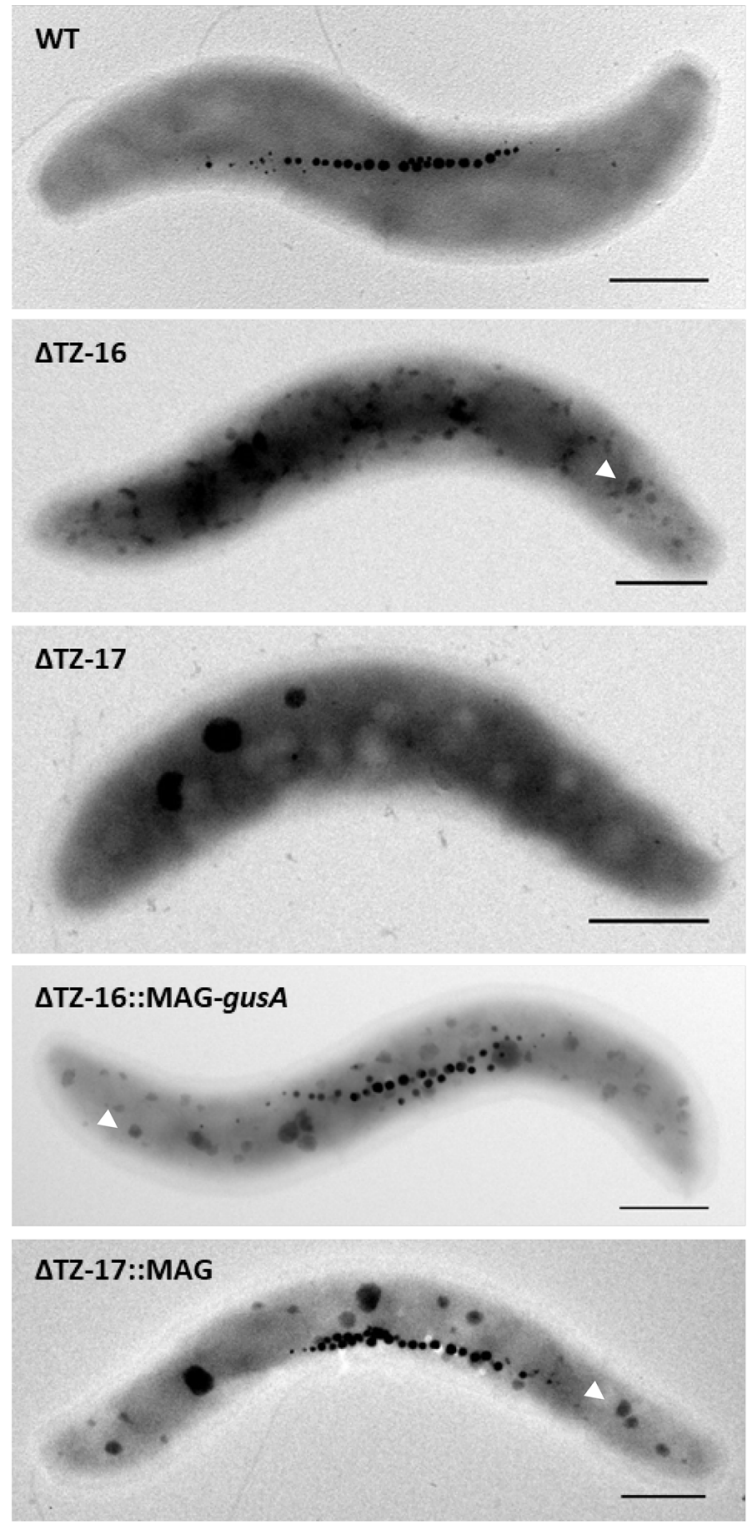

c

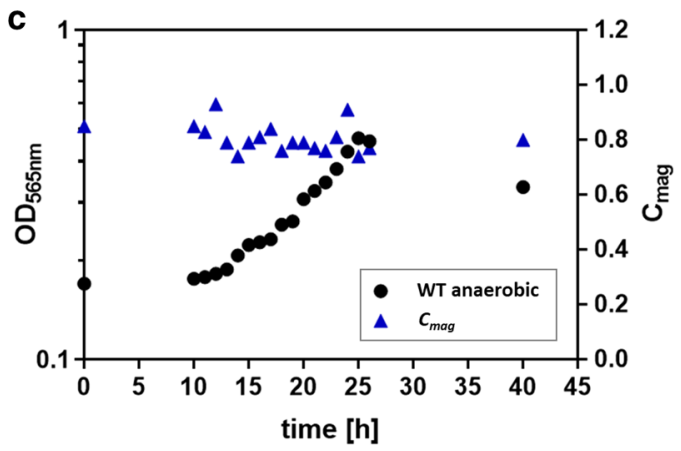

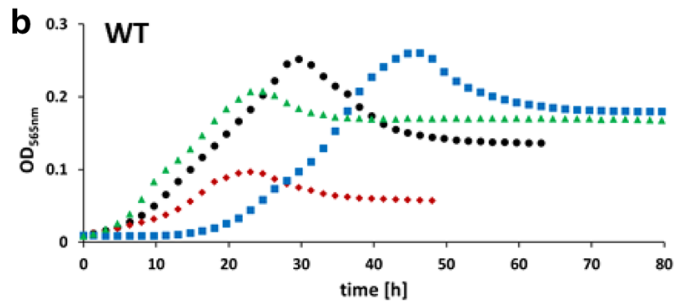
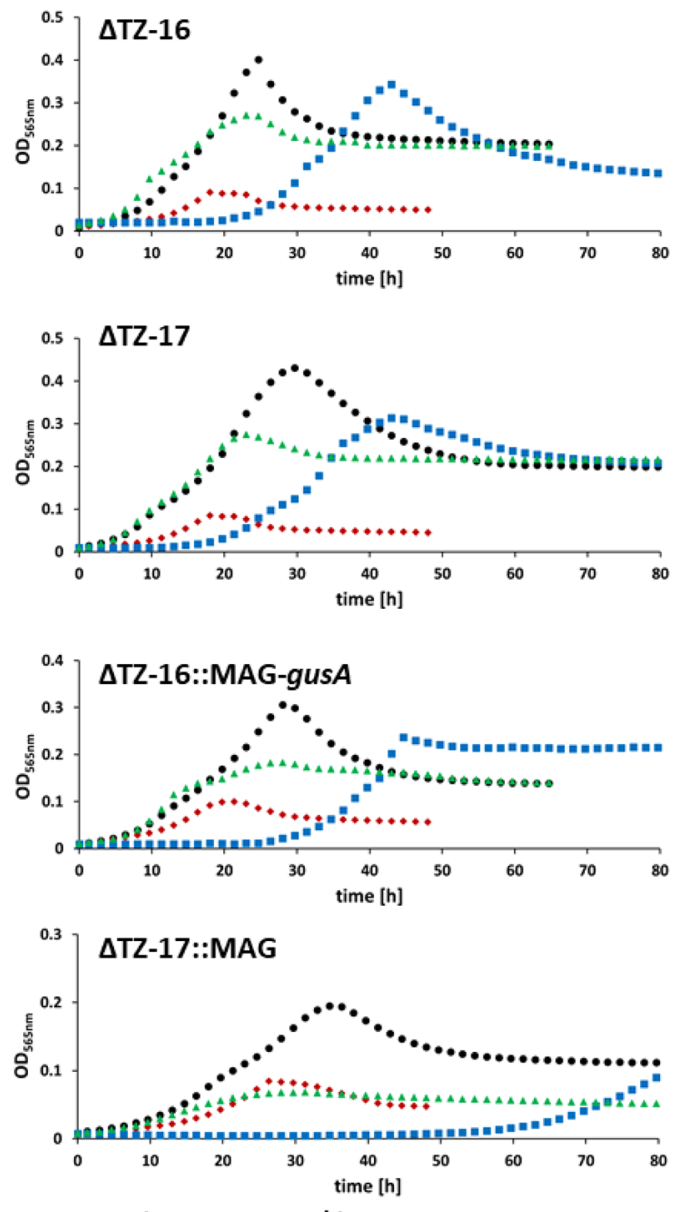

- aerobic * anaerobic $\because \mathrm{H}_{2} \mathrm{O}_{2} \quad 433^{\circ} \mathrm{C}$

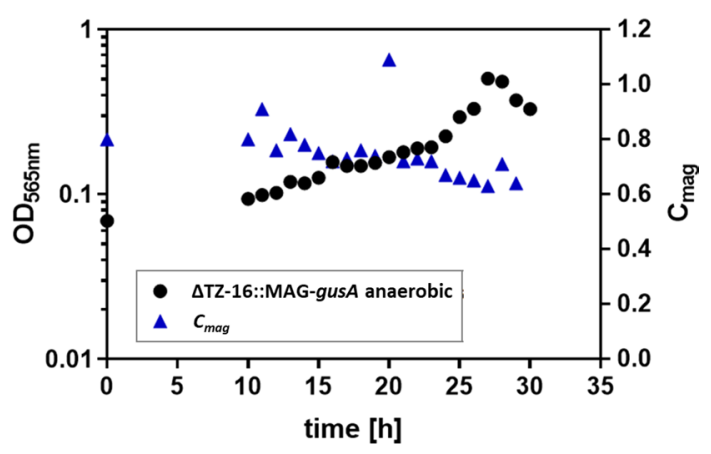


Table 1 Overview of identified mutations in the reporter gene gus $A$

\begin{tabular}{lllll}
\hline & $\begin{array}{l}\text { Point } \\
\text { mutations }\end{array}$ & Insertions & Deletions \\
\cline { 3 - 4 } & & Tn-tandem & $\begin{array}{l}\text { ISMgr2 } \\
\text { (TnpA/B) }\end{array}$ & \\
\hline t0 & 64 & 32 & - & - \\
WT-gusA & 60 & 6 & - & - \\
$\Delta$ TZ-16::MAG-gusA & 90 & 9 & - & - \\
$\triangle T$ TZ-17::MAG-gusA & 87 & & & \\
t10 & & 30 & 8 & 2 \\
WT-gusA & 56 & 15 & - & - \\
$\triangle T$ TZ-16::MAG-gusA & 81 & 10 & - & - \\
$\triangle T$ TZ-17::MAG-gusA & 86 & & & \\
\hline
\end{tabular}

strains of the eliminated parts of the MAI [53]. Microplate-scale experiments with strains $\Delta$ TZ-16::MAG-gus $A$ and $\Delta \mathrm{TZ}-17::$ MAG-gusA under aerobic and anaerobic nitrate-reducing conditions indicated WT-like or slightly delayed cell growth compared to WT (Fig. 6b). To analyze growth at higher cell densities, strains $\Delta$ TZ-16::MAG-gus $A$ and $\Delta$ TZ-17::MAG-gusA were in addition cultivated in a larger volume (3 l) in a bioreactor under controlled anaerobic conditions, which are known to be optimal for magnetosome biomineralization $[28,62]$. Figure $6 c$ shows exemplary results for strain $\Delta$ TZ-16::MAG-gusA compared to the WT. Both strains reached a final OD of $>0.5$, compared to only ca. 0.1 typically observed in microplate growth. Again, growth of strains $\Delta$ TZ-16::MAG-gusA and $\Delta$ TZ-17::MAG-gusA was WT-like, indicating that loss of the eliminated genes was neutral for growth under controlled conditions. Strains $\Delta$ TZ-16::MAG-gusA and $\Delta$ TZ-17::MAG were also tested regarding their growth performance after challenging them with the antibiotic MMC. Similar as the single deletion strain of the putative phage integrase gene hin2, both strains survived concentrations up to $0.3 \mu \mathrm{g} /$ $\mathrm{ml}$ MMC, while WT was entirely inhibited at $0.3 \mu \mathrm{g} / \mathrm{ml}$ MMC (Additional file 1: Fig. S4).

\section{Stability of the reporter gene gusA and the magnetic phenotype}

To analyze whether the combined multiple deletion of IS elements in M. gryphiswaldense affects the incidence of spontaneous mutations, we employed an assay to estimate the genetic stability of expressed foreign genes as well as the stability of the magnetic phenotype using the reporter gene gusA as a 'trap' (Additional file 1: Fig. S5A), similar as reported for other marker genes in different bacteria [64]. Mutational inactivation of gusA causes the loss of the ability to cleave X-Gluc into blue dye, hence resulting in white (magnetosome-free) or brownish (magnetosome forming) colonies (Additional file 1: Fig. S5). After ten sequential passages under aerobic conditions (alternating between $4 \mathrm{~h}$ at $4{ }^{\circ} \mathrm{C}$ and $44 \mathrm{~h}$ at $28{ }^{\circ} \mathrm{C}$, conditions which were previously found to favor spontaneous mutations [41], 12 independent parallels (equivalent to $\sim 4.2 * 10^{3}$ cells for each strain and time point) were plated and visually screened. Out of $\sim 2.5^{*} 10^{4}$ cells in total, $2-3 \%$ of colonies had lost their blue color. Overall, among the about $7.1 * 10^{2}$ white clones, we analyzed 192 white clones of each WT-gusA, $\Delta$ TZ-16::MAG-gus $A$ and $\Delta$ TZ-17::MAG-gusA in which gusA was found to be inactivated by different types of mutations, including point mutations $(80.6 \%)$, insertions $(19.1 \%)$ and deletions $(0.3 \%)$. The majority of the point mutations observed were base deletions (40\%) and insertions (50\%) causing frame shifts, while base substitutions represented the minority (10\%). The types of point mutation were independent from time point or strain, and most mutations were found within a range of $500 \mathrm{bp}$ of the gusA gene encoding the catalytic center of the GusA enzyme [65]. Furthermore, deletions of $62 \mathrm{bp}$ of the gusA gene were found within the $25 \% \mathrm{~N}$-terminal portion of the GusA protein.

All larger gusA insertions were found to belong exclusively to the two types of IS elements that we had already identified in our preliminary experiments described above [ISMgr2 (7.3\%) and tn-tandem (92.7\%)], present both in cells before (t0) and after (t10) passaging. The high frequency observed for tn-tandem insertions might have been probably caused by its high abundance or close proximity $(\sim 11.4 \mathrm{~kb})$ of a copy to the gusA reporter. While the total number of mutations between time points t 0 and $t 10$ did not significantly vary (Table 1 ), the number of all insertions was substantially reduced by ca. 60-75\% in $\Delta$ TZ-16::MAG-gusA and $\Delta$ TZ-17::MAG-gus $A$ compared to WT-gusA, likely due to the successful elimination of several active IS elements described above.

In addition to mutations in gusA, reduction or loss of the magnetic phenotype was found in a minority of clones from white or brown colonies which had lost their blue color. Reduced magnetic phenotypes displaying WT-like magnetite crystals flanked by flake-like particles could be observed in several of WT-gusA clones after ten passages (Additional file 1: Fig. S5B), which likely indicates a second mutation (i.e., in addition to the point mutations within gusA) in mamXYop [61]. Furthermore, the loss of the magnetic phenotype coincident with gusA inactivation could be observed in three clones of $\Delta$ TZ-16::MAG-gusA for time point t10. This could be the result of spontaneous homologous recombination between identical stretches of DNA in this partially merodiploidic strain. 


\section{Discussion}

In this study, we established an approach for large-scale combinatory genome reduction of the magnetotactic bacterium M. gryphiswaldense. By repeated circles of deletion, we generated a library of strains in which different multiple genomic segments were erased. These strains might each serve as different starting points in future genome streamlining approaches by recombination with further favorable deletions and insertions.

In total, we completed the combination of 16 single deletions from this and our previous work [53] into each of the two strains $\Delta \mathrm{TZ}-16$ and $\Delta \mathrm{TZ}-17$, in which in addition large parts of the fragmented MAI were functionally replaced by a compact version of the magnetosome biosynthesis gene clusters.

On average, one round of deletion typically took about 3 weeks, and after some technical streamlining, the 16 subsequent rounds could have been completed in about 12 months of work. Independent of the target size, all rounds of successful deletions were largely completed with similar efficiencies as for respective single deletions. An exception was the unsuccessful deletion of the M04 region which might be especially problematic due to the abundance of transposon genes close to the regions targeted for homologous recombination. Several undesired mutations and spontaneous rearrangements were found to have occurred during recursive deletions. This emphasizes the need of genome resequencing of key intermediates and final strains. Again, most of these spontaneous rearrangements were caused by either homologous or illegitimate recombination and could be traced back to the spontaneous inactivation of the lethal galK marker harbored on the suicide vectors for homologous recombination, thereby preventing effective counterselection of proper double-crossovers.

However, despite of these caveats, we succeeded in the construction of one final strain $(\Delta \mathrm{TZ}-17)$ with a genome reduction by non-overlapping $\sim 227,600 \mathrm{bp}$, which is equivalent to about $5.5 \%$ of the entire genome. In this strain all targeted deletions and the reinsertion of the compacted magnetosome gene clusters were found to be exactly as intended, with only few minor spontaneous mutations in regions irrelevant for growth and magnetosome biosynthesis under laboratory conditions. This confirms that if used with caution, the method is sufficiently efficient and reliable for multiple genome editing.

In other bacteria, multiple genome reductions of different extents by similar approaches were previously reported. For example, one of the first studies in E. coli K12 resulted in a genome reduction up to $15 \%$ [47], and the genome of $E$. coli could be further shrunk by $>29 \%$, changing cell size and nucleoid organization of engineered cells [66]. A "MiniBacillus" was constructed from
Bacillus subtilis, in which a total of $42.3 \%$ was eliminated [67]. However, top-down genome reduction approaches in model organisms other than E. coli and B. subtilis have been more limited, and in some cases involved the combined, stepwise efforts of several labs [43]. For example, in C. glutamicum multiple approaches resulted first in the targeted deletion of 11 distinct regions with a total size of 250 kilobase pair (kbp) [68, 69], followed by an untargeted approach via insertion and excision [70]. In another random approach, 42 mutants in a range of $0.2-186 \mathrm{~kb}$ were generated, which revealed a total of $393.6 \mathrm{~kb}(11.9 \%)$ of the C. glutamicum R genome to be non-essential under standard laboratory conditions [70]. More recently, five of the 36 single large deletions identified by Unthan et al. [46] were later combined in a chassis strain of C. glutamicum, in which $13.4 \%$ of the genome were eliminated [45]. Similar approaches with $P$. putida resulted in genome reductions of 4.1\% [71], 4.3\% [48] and $4.12 \%$ [72], respectively, as well as in Lactococcus lactis (2.83\% reduction) [73], Streptomyces avermitilis (1.4 Mb reduction) [74, 75], while in $S$. chattanoogensis $1.3 \mathrm{Mb}$ and $0.7 \mathrm{Mb}$ regions were eliminated [76]. With a comparable reduction by nearly $5.5 \%$ of the genome, our study represents the first proof-of-principle for the feasibility of similar targeted approaches in a magnetotactic bacterium.

While many of the genome streamlining approaches described above led to beneficial properties, such as improved growth and recombinant protein production, as well as robustness against several stresses [34, $45,47,50,77]$, others resulted in negative effects, such as growth deficiencies, decreased resistance against antibiotics and under several stress conditions, and reduced transformation efficiencies [45, 78]. In our study, most deletions were neutral with respect to magnetosome biosynthesis and growth. For example, our preliminary analysis suggested that neither the conjugation efficiency with replicative and insertional plasmids, nor the weak latent propensity of spontaneous cell lysis was affected in strains $\triangle \mathrm{TZ}$-16::MAG-gusA and $\Delta$ TZ-17::MAG-gusA (data not shown). As observed in our previous study, deletion of mamABop in $\triangle \mathrm{TZ}-16$ and $\Delta \mathrm{TZ}-17$ resulted in a growth advantage which became lost after 're-magnetization' by complementation. Among the several putative prophage genes of M. gryphiswaldense, only deletion of the recombinase gene hin2 from P6 had an effect and resulted in a slightly improved resilience to mitomycin c (MMC)induced stress in the final strains. This provides an indirect hint that P6 may be an active prophage, whose excision might be induced by MMC in WT cells, but further work, such as the identification of phage particles, will be necessary to confirm this. However, the 
combined deletion of other phage-related genes did neither further increase MMC resistance, nor generally enhance growth. On the contrary, deletion of the M13 region and prophage genes slightly impaired growth in the presence of oxidative stress, possibly for similar reasons as suggested by Wang et al. [78], who found that the presence of cryptic prophages may help bacteria to cope with adverse conditions and provide multiple benefits. For comparison, $\Delta \mathrm{TZ}-16$ lacks the $\Delta \mathrm{M} 13$ deletion and therefore could be useful as an alternative parent strain with improved growth characteristics in follow-up genome streamlining studies.

From the $\sim 120$ transposable elements predicted in the $4.155 \mathrm{Mbp}$ genome of $M$. gryphiswaldense, 30 are encoded within the ca. $100 \mathrm{~kb}$ MAI, and nine in addition in its $\sim 33 \mathrm{~kb}$ adjacent region $[1,53]$. However, our systematic approach revealed that only a minority of them, belonging to two families, seems to be responsible for the majority of spontaneous insertions. We detected an increased stability of the reporter gusA in both final multiple deletion strains, which was likely a result of the successful elimination of all ISMgr2 elements described above, including one from the MAI. Future approaches should also aim for the removal of ISMgr2-1, ISMgr2-2 and ISMgr2-3 which might further decrease the rate of spontaneous mutations. However, deletion of multiple copies of the $t n$-tandem, the second group of identified troublemakers, or even the generation of a chassis stripped of all copies as accomplished in several other bacteria $[51,52]$ is currently not within realistic reach, due to the numerous abundance and extensive sequence similarity between multiple copies of IS elements, as well as their persistent tendency to spread during genetic manipulation.

\section{Conclusion}

Overall, in this study we succeeded in further domestication and large-scale engineering of magnetotactic bacteria and showed the potential of combining multiple scarless deletions with high precision. We also generated a library of deletions, which represent building blocks for recombination with favorable deletions and insertions that can be used for the construction of improved 'chassis' strains in the future. Ultimately, this may turn M. gryphiswaldense into a versatile platform and microbial cell factory for synthetic biology and magnetosome production.

\section{Methods}

Bacterial strains, vectors, and cultivation conditions

Bacterial strains and plasmids used in this work are listed in Additional file 1: Table S1. E. coli strains were grown as previously reported [79]. E. coli WM3064 strains were grown in lysogeny broth (LB) medium supplemented with $25 \mu \mathrm{g} / \mathrm{ml}$ (final concentration) kanamycin $(\mathrm{Km})$, and $1 \mathrm{mM}$ DL- $\alpha, \varepsilon$-diaminopimelic acid (DAP) at $37{ }^{\circ} \mathrm{C}$. Liquid cultures of $M$. gryphiswaldense strains were grown microaerobically in flask standard medium (FSM) [28] at $28{ }^{\circ} \mathrm{C}$ under moderate shaking (120 rpm). Strains carrying the suicide or complementation plasmid were cultivated by adding $5 \mu \mathrm{g} / \mathrm{ml} \mathrm{Km}$. For cultivation on solid LB medium or FSM, $1.5 \%(\mathrm{w} / \mathrm{v})$ agar was added. Cultivation from single M. gryphiswaldense colonies was conducted by transferring cell material into $150 \mu \mathrm{l} \mathrm{FSM} \mathrm{in} \mathrm{96-deep-}$ well-plates (Eppendorf, Hamburg, Germany), prior to gradually increasing the culture volume. Optical density (OD) and magnetic response $\left(C_{\text {mag }}\right.$ i.e., a proxy for the average magnetic orientation of bacterial cells in liquid media based on light-scattering) of cells in the exponential growth phase were measured photometrically at $565 \mathrm{~nm}$ as previously described [63].

Growth experiments of M. gryphiswaldense were performed by using pre-cultures grown for two daily passages under microaerobic conditions at $28{ }^{\circ} \mathrm{C}$. Cultures were adjusted to an initial OD of 0.01 and grown in a microplate reader (Tecan) under aerobic conditions at $28{ }^{\circ} \mathrm{C}$ or moderate heat stress at $33^{\circ} \mathrm{C}$. For induction of oxidative stress, $20 \mu \mathrm{M} \mathrm{H}_{2} \mathrm{O}_{2}$ were added prior to starting the growth experiments.

For cell growth after mitomycin C (MMC) induction, pre-cultures were adjusted to an initial OD of 0.08 and treated with MMC concentrations of $0.1-0.3 \mu \mathrm{g} / \mathrm{ml}$ for $8 \mathrm{~h}$. Non-induced strains $(0 \mu \mathrm{g} / \mathrm{ml})$ served as controls. Then cultures were washed twice in FSM, and an initial OD of 0.01 was used to start growth experiments in the microplate reader under aerobic conditions at $28{ }^{\circ} \mathrm{C}$.

In preliminary experiments, conditions could be defined (i.e. incubation with $0.2 \mu \mathrm{g} / \mathrm{ml} \mathrm{MMC} \mathrm{for} 8 \mathrm{~h}$ ) in which growth of the WT was already somewhat impaired, yet still reached substantial yields (final OD of ca. 0.3), while slightly increased MMC concentrations $(0.3 \mu \mathrm{g} / \mathrm{ml})$ entirely abolished growth. Therefore, we used $8 \mathrm{~h}$ and $0.2-0.3 \mu \mathrm{g} / \mathrm{ml} \mathrm{MMC}$ as efficient incubation conditions to analyze survival of mutants compared to the WT strain.

For cultivation in the fermenter, modified FSM was used adding $10 \mathrm{mM} \mathrm{NaNO}_{3}$ instead of $4 \mathrm{mM} \mathrm{NaNO}$ as alternative electron acceptor under anaerobic conditions. Growth experiments of WT and final strains were performed in 31 Bioflow $^{\circledR} 320$ reactors (Eppendorf Bioprocess) equipped for the automatic control of $\mathrm{pH}$ (with $\mathrm{H}_{2} \mathrm{SO}_{4}$ or $\mathrm{KOH}$ ), temperature, agitation, and nitrogen concentration. Data were directly saved at unit or in BioCommand software. Seed train was prepared $56 \mathrm{~h}$ before 
inoculation in falcon tubes and scaled up to $1 \mathrm{l}$ flasks under anaerobic conditions.

\section{Molecular and genetic techniques}

Oligonucleotides used as primers for amplification of DNA fragments were inferred from the working draft genome sequence of $M$. gryphiswaldense (GenBank accession number CP027526) [80] and purchased from Sigma-Aldrich (Steinheim, Germany). Construction of plasmids was performed by standard recombinant techniques as described in Zwiener et al. [53]. Generated constructs were sequenced by Macrogen Europe (Amsterdam, Netherlands) and sequence data analyzed with Geneious 8.0.5 (Biomatters Ltd).

\section{Construction of markerless gene deletion vectors and mutants}

Generation of single and multiple deletion mutants and WT-gusA insertion mutant was carried out by a tailored galK counterselection system as previously reported [53, 81].

We used chromosomal insertion and expression of magnetosome biosynthetic gene clusters, since previous work has shown that episomal expression in M. gryphiswaldense resulted in instability and inhomogenous expression of foreign and magnetosome genes [82, 83]. Multiple deletion mutants were complemented with the pMDJM3 cassette, a recyclable variant of pTpsMAG1 [60] containing lox sites next to the antibiotic marker and all operons necessary for magnetosome formation. For insertion of the chromogenic marker gusA into pMDJM3, RedET recombineering [84] was performed according to BAC Subcloning Kit (Gene Bridges) technical protocols.

\section{Analytical methods}

\section{Analysis of putative prophages}

Analysis of putative prophages was performed by the phage search tool PHAST [55]. In PHAST, a prophagelike element was considered incomplete if its completeness score was less than 60 , questionable if the score was in the range between 60 and 90 , and complete if the score was above 90 .

\section{Re-sequencing of genomic DNA}

Genomic DNA was isolated following the manual instructions of Quick-DNA Midiprep Plus Kit (Zymo Research Europe $\mathrm{GmbH}$ ). For each isolated gDNA, two sequencing libraries were arranged, one for sequencing on the MiSeq platform (Illumina Inc, NL), and the second for sequencing on the GridION platform [Oxford Nanopore Technologies (ONT), UK]. The former was established using the TruSeq DNA PCR-free Library Kit (Illumina Inc., The Netherlands) and was carried out in a $2 \times 300$ nt run using a 600 cycle MiSeq Reagent Kit v3 (Illumina Inc, The Netherlands). For ONT sequencing, the Ligation Sequencing Kit SQK-LSK109 was used to arrange the libraries, which were in turn run on a R9.4.1 flow cell. Basecalling of the raw ONT data was carried out with GUPPY v3.2.8 [85]. For assembly, three assemblers were used: the CANU assembler v1.8 [86] was utilized to assemble the ONT data. The resulting assembled contigs were polished applying first the ONT data with RACON v1.3.3 [87] and MEDAKA v0.11.5 (Oxford Nanopore Technologies), both relying on MINIMAP2 v2.17-r943 [88] for mapping, followed by switching to the Illumina data and the PILON polisher v1.22 [89] for a total of 10 rounds. For the first 5 rounds, BWA MEM [90] was utilized as a mapper, for the final 5 cycles, BOwTIE2 [91] was applied. In addition, the Illumina data was assembled using NEWBLER v2.8 [92] and both data sets were gathered using UNICYCLER [93]. All assemblies were compared with each other and examined for synteny using R2CAT [94]. All three assemblies were combined and manually curated using CONSED [95]. Annotation of the finished genomes was carried out using PROKKA v1.11 [96] SNPs and small indels were identified using SNIPPY v4.0 [97] while larger rearrangements were recognized manually using SNAPGENE (GSL Biotech).

\section{Preparation of samples for transmission electron microscopy (TEM)}

For conventional transmission electron microscopy (TEM) of cell and magnetosome morphologies, cultures were grown under microoxic conditions in FSM at $28^{\circ} \mathrm{C}$. Overnight cultures were fixed in $1.5 \%$ formaldehyde and adsorbed onto carbon-coated copper-mesh grids (Science Services, Munich, Germany). TEM was performed on a JEOL 1400 (Japan) with an acceleration voltage of $80 \mathrm{kV}$ and micrographs were analyzed using the software ImageJ [98].

\section{Genetic stability assay}

To test genetic stability of the reporter gusA, overnight cultures were transferred to 96-well-plates and incubated for ten passages under aerobic conditions alternating between $4 \mathrm{~h}$ at $4{ }^{\circ} \mathrm{C}$ and $44 \mathrm{~h}$ at $28{ }^{\circ} \mathrm{C} .12$ independent parallels of each strain were plated on FSM agar moistened with $250 \mu \mathrm{l}$ of a $10 \mathrm{mg} / \mathrm{ml} \mathrm{X-Gluc}$ stock solution on its surface. Clones producing active GusA could be visually screened by their blue color, while mutations inside gusA resulted in the loss of the ability to cleave X-Gluc, and thus in in white or brownish colonies after 7-10 days of incubation at $28{ }^{\circ} \mathrm{C}$. Colonies were counted at time points $0(\mathrm{t} 0)$ and after ten passages ( $\mathrm{t} 10)$ and mutations identified by PCR and sequencing. 


\section{Supplementary Information}

The online version contains supplementary material available at https://doi. org/10.1186/s12934-021-01517-2.

\section{Additional file 1 of "Towards a 'chassis' for bacterial magnetosome biosynthesis: genome streamlining of Magnetospirillum gryphiswaldense by multiple deletions": Table S1. Overview of all} single deletion mutants which were also combined in strains $\triangle T Z-16$ and $\Delta T Z-17$. Table S2. Overview of primers used in this study. UF $=$ upstream forward; $U R=$ upstream reverse; $D F=$ downstream forward; $D R=$ downstream reverse. Figure $\mathbf{S} 1$. Molecular organization of nif operon in $M$. gryphiswaldense. The deleted nitrogen fixation cluster comprises 16 genes necessary for nitrogen fixation (shown in red): nifWABZTHDK, fiXABC, draGT and three ferredoxins (MSR1_18560; MSR1_18600; MSR1_18640). Black arrows represent other genes encoding a putative rubrerythrin protein (MSR1_18580), a SIR2-like domain containing protein (MSR1_18630), a GAF domain-containing protein (MSR1_18650), a biliverdin-producing heme oxygenase (MSR1_18660) and a tRNA (MSR1_18670). Figure S2. Phenotypic characterization of multiple deletion mutants. Electron micrographs of combinatorial deletion mutants $\Delta T Z-01-\Delta T Z-15$. Scale bars: left columns $500 \mathrm{~nm}$; right columns $100 \mathrm{~nm}$. Cell growth of strains $\Delta T Z-01-\Delta T Z-15$ under aerobic and anaerobic conditions as well as oxidative stress $\left(\mathrm{H}_{2} \mathrm{O}_{2}\right)$ and moderate heat stress $\left(33^{\circ} \mathrm{C}\right)$. Each strain was analyzed in triplicates and each curve shows the average. Figure $\mathbf{S} 3$. Genetic organization of the $\mathrm{Km}^{\mathrm{r}}$, false positive mutant $\Delta \mathrm{TZ}-15 \Delta \mathrm{M} 04 \mathrm{~K} 752$ $\mathrm{Km}^{\mathrm{r}}$. The targeted M04 had not been deleted but was still maintained in the genome. A large part ( 9.1 kb) of the $10.2 \mathrm{~kb}$ deletion vector PORFM-GalK-MO4 harboring the $\mathrm{Km}^{\prime}$ gene was found to be inserted at the intended site, but harboring a spontaneous duplication of both the upstream and downstream homologous regions intended for targeted insertion of the deletion construct by homologous recombination. In addition, the galK gene was inactivated by insertion of a copy of the IS element ISMgr2 into the central region. Figure S4. Growth profiles of these strains induced with $M M C$ with concentrations between 0.2 and $0.3 \mathrm{\mu g} / \mathrm{ml} \mathrm{MMC}$, induced $8 \mathrm{~h}$. Cells were washed twice, adjusted to initial $\mathrm{OD}$ and growth experiments started at $28^{\circ} \mathrm{C}$ under aerobic conditions and each strain was analyzed in triplicates while each curve shows its average (standard deviation $<5 \%$ ). Figure $\mathbf{S} 5$. Experimental procedure of the genetic stability assay (A) and identified magnetosome phenotypes (B). Blue arrows indicate blue colonies while white/brown colonies are marked by black arrows (A). TEM micrographs (B) show WT-like magnetosome chains (upper micrograph) and flake-like particles (lower micrograph, white arrows) could be observed in several of WT-gusA clones after ten passages. Scale bars: $100 \mathrm{~nm}$.

\section{Abbreviations}

MAI: Magnetosome Island; WT: Wild type; IS element: Insertion element; MNP: Magnetic nanoparticles; MMC: Mitomycin C; tn-tandem: Transposon-tandem; $\mathrm{Km}^{\mathrm{r}}$ : Kanamycin resistant; $\mathrm{Km}^{\mathrm{s}}$ : Kanamycin sensitive; EDP: Electron dense particles; X-Gluc: 5-Bromo-4-chloro-3-indolyl- $\beta$-D-glucuronide; DAP: DL-a, $\varepsilon$ Diaminopimelic acid.

\section{Acknowledgements}

This work was supported by European Research Council (ERC) under the European Union's Horizon 2020 research and innovation program (Grant No. 692637 to D.S.), and by the Federal Ministry of Education and Research (BMBF) (Grant MagBioFab to D.S. and R. U.). We thank S. Geimer and M. Schüler for assistance with transmission electron microscopy, and J. Mansky for the help in the construction of pMDJM3 plasmid.

\section{Authors' contributions}

TZ and DS conceived the study and designed the experiments. TZ carried out the genetic manipulations and the characterization of the strains. TZ, DS, FM and RU designed genetic stability assay. MD designed and generated plasmid PMDJM3. CR, TB and JK performed resequencing of strains. TZ and DS wrote the manuscript. All authors read and approved the final manuscript.

\section{Funding}

Open Access funding enabled and organized by Projekt DEAL. This study was supported by the European Research Council (ERC) under the European Union's Horizon 2020 research and innovation program (Grant No. 692637 to D.S.), and the Federal Ministry of Education and Research (BMBF) (Grant MagBioFab to D.S. and R.U.).

\section{Availability of data and materials}

The datasets used and analyzed during the current study are available from the corresponding author on reasonable request.

\section{Ethics approval and consent to participate}

Not applicable.

\section{Consent for publication}

All authors have read and approved the current version of the manuscript.

\section{Competing interests}

The authors declare that they have no competing interests.

\section{Author details}

${ }^{1}$ Department of Microbiology, University of Bayreuth, Bayreuth, Germany.

${ }^{2}$ Institute of Bioengineering, Research Center of Biotechnology of the Russian Academy of Sciences, Moscow, Russia. ${ }^{3}$ Center for Biotechnology, University of Bielefeld, Bielefeld, Germany

Received: 23 October 2020 Accepted: 12 January 2021

Published online: 04 February 2021

\section{References}

1. Uebe R, Schüler D. Magnetosome biogenesis in magnetotactic bacteria. Nat Rev Microbiol. 2016;14:621-37.

2. Lefèvre $C T$, Bazylinski DA. Ecology, diversity, and evolution of magnetotactic bacteria. Microbiol Mol Biol Rev. 2013;77(3):497-526.

3. Faivre D, Schüler D. Magnetotactic bacteria and magnetosomes. Chem Rev. 2008;108(11):4875-98.

4. Sun C, Lee JSH, Zhang M. Magnetic nanoparticles in MR imaging and drug delivery. Adv Drug Deliv Rev. 2008;60(11):1252-65.

5. Taukulis R, Widdrat M, Kumari M, Heinke D, Rumpler M, Tompa É, Uebe R, Kraupner A, Cebers A, Schüler D, Pósfai M, Hirt AM, Faivre D. Magnetic iron oxide nanoparticles as MRI contrast agents-a comprehensive physical and theoretical study. Magnetohydrodynamics. 2015;51(4):721-47.

6. Alphandéry E. Applications of magnetosomes synthesized by magnetotactic bacteria in medicine. Front Bioeng Biotechnol. 2014;2:5.

7. Vargas G, Cypriano J, Correa T, Leão P, Bazylinski DA, Abreu F. Applications of magnetotactic bacteria, magnetosomes and magnetosome crystals in biotechnology and nanotechnology: mini-review. Molecules. 2018;23(10):2438

8. Orlando T, Mannucci S, Fantechi E, Conti G, Tambalo S, Busato A, Innocenti C, Ghin L, Bassi R, Arosio P, Orsini F, Sangregorio C, Corti M, Casula MF, Marzola P, Lascialfari A, Sbarbati A. Characterization of magnetic nanoparticles from Magnetospirillum gryphiswaldense as potential theranostics tools. Contrast Media Mol Imaging. 2016;11(2):139-45.

9. Heinke D, Kraupner A, Eberbeck D, Schmidt D, Radon P, Uebe R, Schüler D, Briel A. MPS and MRI efficacy of magnetosomes from wild-type and mutant bacterial strains. IJMPI. 2017;3(2):1706004.

10. Kraupner A, Eberbeck D, Heinke D, Uebe R, Schüler D, Biel A. Bacterial magnetosomes-nature's powerful contribution to MPI tracer research. Nanoscale. 2017;9(18):5788-93.

11. Lang C, Schüler D. Biogenic nanoparticles: production, characterization, and application of bacterial magnetosomes. J Phys Condens Matter. 2006;18:2815-28.

12. Lisy MR, Hartung A, Lang C, Schüler D, Richter W, Reichenbach JR, Kaiser WA, Hilger I. Fluorescent bacterial magnetic nanoparticles as bimodal contrast agents. Invest Radiol. 2007;42(4):235-41.

13. Schwarz S, Fernandes F, Sanroman L, Hodenius M, Lang C, Himmelreich U, Fama G, Schmitz-Rode T, Schüler D, Hoehn M, Zenke M, Hieronymus T. Synthetic and biogenic magnetite nanoparticles for tracking of stem cells and dendritic cells. J Magn Magn Mater. 2009;321(10):1533-8. 
14. Hergt R, Dutz S, Röder M. Effects of size distribution on hysteresis losses of magnetic nanoparticles for hyperthermia. J Phys Condens Matter. 2008:20:385214

15. Alphandéry E, Guyot F, Chebbi I. Preparation of chains of magnetosomes, isolated from Magnetospirillum magneticum strain AMB-1 magnetotactic bacteria, yielding efficient treatment of tumors using magnetic hyperthermia. Int J Pharm. 2012;434(1-2):444-52.

16. Mickoleit F, Schüler D. Generation of multifunctional magnetic nanoparticles with amplified catalytic activities by genetic expression of enzyme arrays on bacterial magnetosomes. Adv Biosyst. 2018;2:1700109.

17. Mickoleit F, Lanzloth C, Schüler D. A versatile toolkit for controllable and highly selective multifunctionalization of bacterial magnetic nanoparticles. Small. 2020;16(16):e1906922.

18. Pollithy A, Romer T, Lang C, Müller FD, Helma J, Leonhardt H, Rothbauer U, Schüler D. Magnetosome expression of functional camelid antibody fragments (nanobodies) in Magnetospirillum gryphiswaldense. Appl Environ Microbiol. 2011;77(17):6165-71.

19. Borg S, Rothenstein D, Bill J, Schüler D. Generation of multi-shell magnetic hybrid nanoparticles by encapsulation of genetically engineered and fluorescent bacterial magnetosomes with $\mathrm{ZnO}$ and $\mathrm{SiO}_{2}$. Small. 2015:11(33):4209-17.

20. Mickoleit F, Schüler D. Generation of nanomagnetic biocomposites by genetic engineering of bacterial magnetosomes. Bioinspired Biomim Nanobiomater. 2018;8(1):86-98.

21. Mickoleit F, Borkner CB, Toro-Nahuelpan M, Herold HM, Maier DS, Plitzko $J M$, Scheibel T, Schüler D. In vivo coating of bacterial magnetic nanoparticles by magnetosome expression of spider silk-inspired peptides. Biomacromolecules. 2018:19(3):962-72.

22. Mickoleit F, Jérôme V, Freitag R, Schüler D. Bacterial magnetosomes as novel platform for the presentation of immunostimulatory, membranebound ligands in cellular biotechnology. Adv Biosyst. 2020;4(3):e1900231.

23. Zeytuni N, Uebe R, Maes M, Davidov G, Baram M, Raschdorf O, Friedler A, Miller Y, Schüler D, Zarivach R. Bacterial magnetosome biomineralizationa novel platform to study molecular mechanisms of human CDF-related Type-II diabetes. PLoS ONE. 2014;9(5):e97154.

24. Schleifer KH, Schüler D, Spring S, Weizenegger M, Amann R, Ludwig W, Köhler M. The genus Magnetospirillum gen. nov. description of Magnetospirillum gryphiswaldense sp. nov. and transfer of Aquaspirillum magnetotacticum to Magnetospirillum magnetotacticum comb. nov. Syst Appl Microbiol. 1991;14:379-85.

25. Schüler $\mathrm{D}$, Monteil $\mathrm{CL}$, Lefèvre $\mathrm{CT}$. Microbe of the month: Magnetospirillum gryphiswaldense. Trends in Microbiol. 2020. https://doi.org/10.1016/j. tim.2020.06.001.

26. Müller F, Schüler D, Pfeiffer D. A compass to boost navigation: cell biology of bacterial magnetotaxis. J Bacteriol. 2020. https://doi.org/10.1128/ JB.00398-20.

27. Lohße A, Kolinko I, Raschdorf O, Uebe R, Borg S, Brachmann A, Plitzko $J M$, Müller R, Zhang Y, Schüler D. Overproduction of magnetosomes by genomic amplification of biosynthesis-related gene clusters in a magnetotactic bacterium. Appl Environ Microbiol. 2016;82(10):3032-41.

28. Heyen U, Schüler D. Growth and magnetosome formation by microaerophilic Magnetospirillum strains in an oxygen-controlled fermentor. Appl Microbiol Biotechnol. 2003;61:536-44.

29. Alphandéry E. Bio-synthesized iron oxide nanoparticles for cancer treatment. J Pharm. 2020;586:119472.

30. Alphandéry E. Applications of magnetotactic bacteria and magnetosome for cancer treatment: a review emphasizing on practical and mechanistic aspects Drug Discov Today. 2020. https://doi.org/10.1016/j.drudis.2020.06.010.

31. Fernández-Castané A, Li H, Thomas ORT, Overton TW. Development of a simple intensified fermentation strategy for growth of Magnetospirillum gryphiswaldense MSR-1: physiological responses to changing environmental conditions. New Biotechnol. 2018;46:22-30.

32. Schüler D. Versuche zur Isolierung und Charakterisierung magnetotaktischer Bakterien. Diplomarbeit, Ernst-Moritz-Arndt Universität Greifswald. 1990

33. Schüler D, Köhler M. The isolation of a new magnetic spirillum. Zentralblatt Mikrobiologie. 1992;147:150-1.

34. Baumgart M, Unthan S, Rückert C, Sivalingam J, Grünberger A, Kalinowski J, Bott M, Noack S, Frunzke J. Construction of a prophage-free variant of Corynebacterium glutamicum ATCC 13032 for use as a platform strain for basic research and industrial biotechnology. Appl Environ Microbiol. 2013:79(19):6006-15.
35. Martínez-García E, Nikel PI, Aparicio T, de Lorenzo V. Pseudomonas 2.0: genetic upgrading of P. putida KT2440 as an enhanced host for heterologous gene expression. Microb Cell Fact. 2014;13:159.

36. Gödeke J, Paul K, Lassak J, Thormann KM. Phage-induced lysis enhances biofilm formation in Shewanella oneidensis MR-1. ISME J. 2011;5(4):613-26.

37. Schübbe S, Kube M, Scheffel A, Wawer C, Heyen U, Meyerdierks A, Madkour MH, Mayer F, Reinhardt R, Schüler D. Characterization of a spontaneous nonmagnetic mutant of Magnetospirillum gryphiswaldense reveals a large deletion comprising a putative magnetosome island. J Bacteriol. 2003;185:5779-90.

38. Ullrich S, Kube M, Schübbe S, Reinhardt R, Schüler D. A hypervariable 130-kilobase genomic region of Magnetospirillum gryphiswaldense comprises a magnetosome island which undergoes frequent rearrangements during stationary growth. J Bacteriol. 2005;187:7176-84.

39. Ullrich S, Schüler D. Cre-lox-based method for generation of large deletions within the genomic magnetosome island of Magnetospirillum gryphiswaldense. Appl Environ Microbiol. 2010;76:2439-44.

40. McCausland HC, Komeili A. Magnetic genes: studying the genetics of biomineralization in magnetotactic bacteria. PLoS Genet. 2020;16(2):e1008499.

41. Kolinko I, Jogler C, Katzmann E, Schüler D. Frequent mutations within the genomic magnetosome island of Magnetospirillum gryphiswaldense are mediated by RecA. J Bacteriol. 2011;193:5328-34.

42. Martínez-García E, Fraile S, Espeso DR, Vecchietti D, Bertoni G, de Lorenzo V. Naked bacterium: emerging properties of a surfome-streamlined Pseudomonas putida strain. ACS Synth Biol. 2020;9(9):2477-92.

43. Martínez-García E, de Lorenzo V. The quest for the minimal bacterial genome. Curr Opin Biotechnol. 2016;42:216-24.

44. Fehér T, Birland V, Pósfai $\mathrm{G}$. In the fast lane: large-scale bacterial genome engineering. J Biotechnol. 2012;169(1-2):72-9.

45. Baumgart M, Unthan S, Kloß R, Radek A, Polen T, Tenhaef N, Müller MF, Küberl A, Siebert D, Brühl N, Marin K, Hans S, Krämer R, Bott M, Kalinowski J, Wiechert W, Seibold G, Frunzke J, Rückert C, Wendisch V, Noack S. Corynebacterium glutamicum chassis $C 1^{*}$ : building and testing a novel platform host for synthetic biology and industrial biotechnology. ACS Synth Biol. 2017;7(1):132-44.

46. Unthan S, Baumgart M, Radek A, Herbst M, Siebert D, Brühl N, Bartsch A, Bott M, Wiechert W, Marin K, Hans S, Krämer R, Seibold G, Frunzke J, Kalinowski J, Rückert C, Wendisch VF, Noack S. Chassis organism from Corynebacterium glutamicum - a top-down approach to identify and delete irrelevant gene clusters. Biotechnol J. 2015;10:290-301.

47. Pósfai G, Plunkett G 3rd, Fehér T, Frisch D, Keil GM, Umenhoffer K Kolisnychenko V, Stahl B, Sharma SS, de Arruda M, Burland V, Harcum SW, Blattner FR. Emerging properties of reduced-genome Escherichia coli. Science. 2006;312(5776):1044-6.

48. Lieder S, Nikel PI, de Lorenzo V, Takors R. Genome reduction boosts heterologous gene expression in Pseudomonas putida. Microb Cell Fact. 2015;14:23.

49. Martínez-García E, Jatsenko T, Kivisaar M, de Lorenzo V. Freeing Pseudomonas putida KT2440 of its proviral load strengthens endurance to environmental stresses. Environ Microbiol. 2015:17(1):76-90.

50. Pfeifer E, Michniewski S, Gätgens C, Münch E, Müller F, Polen T, Millard A, Blombach B, Frunzke J. Generation of a prophage-free variant of the fast-growing bacterium Vibrio natriegens. Appl Environ Microbiol. 2019:85(17):e00853-e919.

51. Choi JW, Yim SS, Kim MJ, Jeong KJ. Enhanced production of recombinant proteins with Corynebacterium glutamicum by deletion of insertion sequences (IS elements). Microb Cell Fact. 2015;14:207.

52. Suárez GA, Renda BA, Dasgupta A, Barrick JE. Reduced mutation rate and increased transformability of transposon-free Acinetobacter baylyi ADP1ISx. Appl Environ Microbiol. 2017;83(17):e01025-e1117.

53. Zwiener T, Mickoleit F, Dziuba M, Rückert C, Busche T, Kalinowski J, Faivre D, Uebe R, Schüler D. Identification and elimination of irrelevant genomic content for magnetosome biosynthesis by large-scale deletion in Magnetospirillum gryphiswaldense. BMC Microbiol. 2021 (Accepted for publication, 2021)

54. de Lorenzo V, Krasnogor N, Schmidt M. For the sake of the bioeconomy: define what a synthetic biology chassis is! New Biotechnol. 2021;60:44-51.

55. Zhou Y, Liang Y, Lynch KH, Dennis JJ, Wishart DS. PHAST: a fast phage search tool. Nucl Acids Res. 2011;39:W347-52. 
56. Engelhardt T, Sahlberg M, Cypionka H, Engelen B. Induction of prophages from deep-subseafloor bacteria. Environ Microbiol Rep. 2011;3:459-65.

57. Siguier P, Gourbeyre E, Chandler M. Bacterial insertion sequences: their genomic impact and diversity. FEMS Microbiol Rev. 2014;38(5):865-91.

58. Bazylinski DA, Dean AJ, Schüler D, Phillips EJP, Levley DR. $\mathrm{N}_{2}$-dependent growth and nitrogenase activity in the metal-metabolizing bacteria, Geobacter and Magnetospirillum species. Environ Microbiol. 2000;2(3):266-73.

59. Araujo ACV, Abreu F, Silva KT, Bazylinski DA, Lins U. Magnetotactic bacteria as potential sources of bioproducts. Mar Drugs. 2015;13(1):389-430.

60. Dziuba MV, Zwiener T, Uebe R, Schüler D. Single-step transfer of biosynthetic operons endows a non-magnetotactic Magnetospirillum strain from wetland with magnetosome biosynthesis. Environ Microbiol. 2020;22(4):1603-18.

61. Raschdorf O, Müller FD, Pósfai M, Plitzko JM, Schüler D. The magnetosome proteins MamX, MamZ and MamH are involved in redox control of magnetite biomineralization in Magnetospirillum gryphiswaldense. Mol Microbiol. 2013;89:872-86.

62. Riese C, Uebe R, Rosenfeldt S, Schenk AS, Jérôme V, Freitag R, Schüler D. An automated oxystat fermentation regime for microoxic cultivation and magnetosome production in Magnetospirillum gryphiswaldense. Microb Cell Fact. 2020;19:206.

63. Schüler D, Uhl R, Bäuerlein E. A simple light-scattering method to assay magnetism in Magnetospirillum gryphiswaldense. FEMS Microbiol Lett. 1995;132:139-45.

64. Bartosik D, Sochacka M, Baj J. Identification and characterization of transposable elements of Paracoccus pantotrophus. J Bacteriol. 2003;185(13):3753-63.

65. Little MS, Ervin SM, Walton WG, Tripathy A, Xu Y, Liu J, Redinbo MR. Active site flexibility revealed in crystal structure of Parabacteroides merdae $\beta$-glucoronidase from human gut microbiome. Protein Sci. 2018;27(12):2010-22

66. Hashimoto M, Ichimura T, Mizoguchi H, Tanaka K, Fujimitsu K, Keyamura K, Ote T, Yamakawa T, Yamazaki Y, Mori H, Katayama T, Kato J. Cell size and nucleoid organization of engineered Escherichia coli cells with a reduced genome. Mol Microbiol. 2005;55(1):137-49.

67. Reuß DR, Commichau FM, Gundlach J, Zhu B, Stülke J. The blueprint of a minimal cell: MiniBacillus. Microbiol Mol Biol. 2016;80(4):955-87.

68. Ikeda M, Nakagawa S. TheCorynebacterium glutamicum genome: features and impacts on biotechnological processes. Appl Microbiol Biotechnol. 2003;62:99-109.

69. Suzuki N, Nonaka H, Tsuge Y, Inui M, Yukawa H. New multiple-deletion method for the Corynebacterium glutamicum genome, using a mutant lox sequence. Appl Environ Microbiol. 2005;71(12):8472-80.

70. Tsuge Y, Suzuki N, Inui M, Yukawa H. Random segment deletion based on IS31831 and Cre/loxP excision system in Corynebacterium glutamicum. Appl Microbiol Biotechnol. 2007;74:1333-41.

71. Leprince A, de Lorenzo V, Völler P, van Passel MWJ, Martins dos Santos VAP. Random and cyclical deletion of large DNA segments in the genome of Pseudomonas putida. Environ Microbiol. 2012;14(6):1444-53.

72. Liang P, Zhang Y, Xu B, Zhao Y, Liu X, Gao W, Ma T, Yang C, Wang S, Liu R. Deletion of genomic islands in the Pseudomonas putida KT2440 genome can create an optimal chassis for synthetic biology applications. Microb Cell Fact. 2020;19:70.

73. Zhu D, Fu Y, Liu F, Xu H, Saris PEJ, Qiao M. Enhanced heterologous protein productivity by genome reduction in Lactococcus lactis NZ9000. Microb Cell Fact. 2017;16:1.

74. Komatsu M, Uchiyama T, Omura S, Cane DE, Ikeda H. Genome-minimized Streptomyces host for the heterologous expression of secondary metabolism. PNAS. 2010;107(6):2646-51.

75. Ikeda H, Shin-ya K, Omura S. Genome mining of the Streptomyces avermitilis genome and development of genome-minimized hosts for heterologous expression of biosynthetic gene clusters. J Ind Microbiol Biotechnol. 2014;41(2):233-50.

76. Bu Q-T, Yu P, Wang J, Li Z-Y, Chen X-A, Mao X-M, Li Y-Q. Rational construction of genome-reduced and high-efficient industrial Streptomyces chassis based on multiple comparative genomic approaches. Microb Cell Fact. 2019;18:16.

77. Umenhoffer K, Draskovits G, Nyerges Á, Karcagi I, Bogos B, Tímár E, Csörgő B, Herczeg R, Nagy I, Pál C, Pósfai G. Genome-wide abolishment of mobile genetic elements using genome shuffling and CRISPR/Cas-assisted
MAGE allows the efficient stabilization of bacterial chassis. ACS Synth Biol. 2017;6(8):1471-83.

78. Wang X, Kim Y, Ma Q, Hong SH, Pokusaeva K, Sturino JM, Wood TK. Cryptic prophages help bacteria cope with adverse environments. Nat Commun. 2010;1:147.

79. Sambrook J, Russell DW. Molecular cloning: a laboratory manual. 3rd ed. Cold Spring Harbor: Cold Spring Harbor Laboratory Press; 2001.

80. Uebe R, Schüler D, Jogler C, Wiegand S. Reevaluation of the complete genome sequence of Magnetospirillum gryphiswaldense MSR-1 with single-molecule real-time sequencing data. Genome Announc. 2018;6(17):e00309-e318.

81. Raschdorf O, Plitzko JM, Schüler D, Müller FD. A tailored galK counterselection system for efficient markerless gene deletion and chromosomal tagging in Magnetospirillum gryphiswaldense. Appl Environ Microbiol. 2014;80(14):4323-30.

82. Borg S, Hofmann J, Pollithy A, Lang C, Schüler D. New vectors for chromosomal integration enable high-level constitutive or inducible magnetosome expression of fusion proteins in Magnetospirillum gryphiswaldense. Appl Environ Microbiol. 2014;80(8):2609-16.

83. Kolinko I, Lohße A, Borg S, Raschdorf O, Jogler C, Tu Q, Pósfai M, Tompa É, Plitzko JM, Brachmann A, Wanner G, Müller R, Zhang Y, Schüler D. Biosynthesis of magnetic nanostructures in a foreign organism by transfer of bacterial magnetosome gene clusters. Nat Nanotechnol. 2014;9:193-7.

84. Muyrers JPP, Zhang Y, Stewart AF. Recombinogenic engineering: new options for cloning and manipulating DNA. Trends in Biochem Sci. 2001:23:325-31.

85. Wick RR, Judd LM, Holt KE. Performance of neural network basecalling tools for Oxford Nanopore sequencing. Genome Biol. 2019;20(1):129.

86. Koren S, Walenz BP, Berlin K, Miller JR, Bergman NH, Phillippy AM. Canu: scalable and accurate long-read assembly via adaptive $k$-mer weighting and repeat separation. Genome Res. 2017;27(5):722-36.

87. Vaser R, Sović I, Nagarajan N, Šikić M. Fast and accurate de novo genome assembly from long uncorrected reads. Genome Res. 2017;27(5):737-46.

88. Li H. Minimap2: pairwise alignment for nucleotide sequences. Bioinformatics. 2018;34(18):3094-100.

89. Walker BJ, Abeel T, Shea T, Priest M, Abouelliel A, Sakthikumar S, Cuomo CA, Zeng Q, Wortman J, Young SK, Earl AM. Pilon: an integrated tool for comprehensive microbial variant detection and genome assembly improvement. PLoS ONE. 2014;9(11):e112963.

90. Li H. Aligning sequence reads, clone sequences and assembly contigs with BWA-MEM. 2013. arXiv:1303.3997.

91. Langmead B, Salzberg SL. Fast gapped-read alignment with Bowtie 2. Nat Methods. 2012;9(4):357-9.

92. Margulies M, Egholm M, Altman WE, Attiya S, Bader JS, Bemben L, Berka $\mathrm{J}$, et al. Genome sequencing in microfabricated high-density picolitre reactors. Nature. 2005;437(7057):376-80.

93. Wick RR, Judd LM, Gorrie CL, Holt KE. Unicycler: resolving bacterial genome assemblies from short and long sequencing reads. PLoS Comput Biol. 2017;13(6):e1005595.

94. Husemann P, Stoye J. r2cat: synteny plots and comparative assembly. Bioinformatics. 2009;26(4):570-1.

95. Gordon D, Green P. Consed: a graphical editor for next-generation sequencing. Bioinformatics. 2013;29(22):2936-7.

96. Seemann T. Prokka: rapid prokaryotic genome annotation. Bioinformatics. 2014;30(14):2068-9.

97. Seemann T. snippy: fast bacterial variant calling from NGS reads. 2015.

98. Abràmoff MD, Magalhães PJ, Ram SJ. Image processing with imageJ. Biophotonics Int. 2004;11:36-42.

\section{Publisher's Note}

Springer Nature remains neutral with regard to jurisdictional claims in published maps and institutional affiliations. 